\title{
Phytochemical Composition, Anti-Inflammatory and ER Stress-Reducing Potential of Sambucus ebulus L. Fruit Extract
}

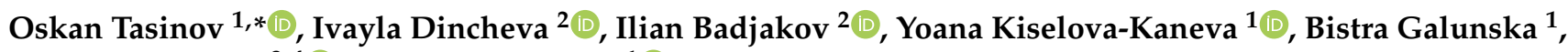 \\ Ruben Nogueiras ${ }^{3,4}\left[\right.$ and Diana Ivanova ${ }^{1}$ (D)
}

1 Department of Biochemistry, Molecular Medicine and Nutrigenomics, Medical University of Varna, 84B Tzar Osvoboditel Blvd., 9002 Varna, Bulgaria; yoana.kiselova@mu-varna.bg (Y.K.-K.); bistra.galunska@gmail.com (B.G.); divanova@mu-varna.bg (D.I.)

2 AgroBioInstitute, Agricultural Academy, 8 Dr. Tsankov Blvd., 1164 Sofia, Bulgaria; ivadincheva@yahoo.com (I.D.); ibadjakov@gmail.com (I.B.)

3 Center for Research in Molecular Medicine and Chronic Diseases (CiMUS), Department of Physiology, University of Santiago de Compostela-Instituto de Investigación Sanitaria, 15782 Santiago de Compostela, Spain; ruben.nogueiras@usc.es

4 CIBER Fisiopatología de la Obesidad y Nutrición (CIBERobn), 15706 Santiago de Compostela, Spain

* Correspondence: oskan.tasinov@gmail.com; Tel.: +359-896-036961

check for updates

Citation: Tasinov, O.; Dincheva, I.; Badjakov, I.; Kiselova-Kaneva, Y.; Galunska, B.; Nogueiras, R.; Ivanova, D. Phytochemical Composition, Anti-Inflammatory and ER Stress-Reducing Potential of Sambucus ebulus L. Fruit Extract. Plants 2021, 10, 2446. https:// doi.org/10.3390/plants10112446

Academic Editor: Othmane Merah

Received: 7 October 2021

Accepted: 9 November 2021

Published: 12 November 2021

Publisher's Note: MDPI stays neutral with regard to jurisdictional claims in published maps and institutional affiliations.

Copyright: (c) 2021 by the authors. Licensee MDPI, Basel, Switzerland. This article is an open access article distributed under the terms and conditions of the Creative Commons Attribution (CC BY) license (https:// creativecommons.org/licenses/by/ $4.0 /)$.

\begin{abstract}
Sambucus ebulus L. (SE) fruits are used for their immunostimulation, hematopoietic and antiviral potential. Recently, we focused on analyzing the mechanism underlying SE fruit aqueous extract's (FAE) immunomodulation and anti-inflammatory activities, with attention to its endoplasmic reticulum (ER) stress-reducing potential. J774A.1 macrophages were treated with SE FAE alone or in conditions of lipopolysaccharides (LPS) stimulation. Using GC-MS and LC-MS/MS, its phytochemical composition was analyzed. To measure transcription and protein levels, we used qPCR and Western blot, respectively. The prevailing phytochemicals in SE FAE were hydroxycinnamic acids, proanthocyanidins and anthocyanins. The content of some amino acids, organic acids, alcohols, fatty acids and esters were newly reported. Extracts exerted an immunostimulation potential by stimulating IL-6, TNF $\alpha, C c l 2, C O X 2$ and $i N O S$ transcription, without inducing ER stress. SE FAE suppressed the LPS-induced transcription of inflammation related genes $(I L-1 \beta, I L-6, T N F \alpha, C c l 2$, Icam-1, Fabp4, COX2, iNOS, Noxo1, IL-1ra, Sirt-1) and reduced the protein levels of iNOS, peIF2 $\alpha$, ATF6 $\alpha$ and CHOP. The effects were comparable to that of salicylic acid. SE suppresses LPS-stimulated inflammatory markers on the transcription and translation levels. Targeting ER stress is possibly another mechanism underlying its anti-inflammatory potential. These findings reveal the potential of SE fruits as a beneficial therapeutic of inflammation and ER stress-related pathological conditions.
\end{abstract}

Keywords: Sambucus ebulus L.; phytochemical composition; anti-inflammatory; ER stress; lipopolysaccharides; macrophages

\section{Introduction}

Traditional medicine is a good source of knowledge about therapeutics, which are consequently researched and successfully implicated in modern pharmaceutical preparations. Sambucus ebulus L. (SE), also known as dwarf elder or dwarf elderberry, is a widely used as wound-healing, anti-nociceptive, anti-rheumatoid, anti-influenza, antibacterial and diuretic medicinal plant in Bulgaria, Turkey, Iran, Lebanon, Romania and BosniaHerzegovina [1-5]. Fresh fruits, jam, tea or decoction of SE fruits are used as immunostimulating and hematopoietic herbal preparations, as well as for the treatment of rheumatoid arthritis and gastrointestinal disorders $[1,2,6]$. The number of modern studies focusing on SE biological activities are growing, but there is still insufficient knowledge regarding molecular mechanisms of action of fresh or dry fruits and various fruit extracts.

Only ripe fruits are used in traditional medicine recipes and the chemical content varies depending on the types of the extract [3,7]. Data from phytochemical analyses in 
the literature reveal that SE fruits are high in polyphenolics, especially anthocyanins and proantchocyanidins, phenolic acids, hydroxycinnamic acids, flavonol glycosides, as well as organic acids, tannins, pectins, resins, vitamin C, volatile substances (eugenol, valeric acid, citronellal etc.), amino acids (including some essential ones), and plant sterols [3,7-16]. Many chromatographic analyses of SE fruit extracts have been carried out up to date, and, still, the information about the presence of certain specific organic compounds remains unclear, especially with regard to soil characteristics, variety of extragents used for sample preparation. Therefore, a detailed phytochemical analysis could be useful, especially in examining the molecular mechanisms of SE fruits on human health.

Numerous studies have established the strong in-vitro antioxidant activity of SE fruit extracts, analyzing its iron chelating, NO radical scavenging, and ABTS cation radical decolorization activity, and their interrelations with polyphenolic and anthocyanin content $[3,7,8]$. The presence of different functional groups in polyphenolics and organic acids found in the tested SE fruit extracts is considered to determine, to a great extent, their antioxidant and anti-inflammatory activities. In oxidatively challenged 3T3-L1 preadipocytes, SE fruit aqueous extract (FAE) acts as modulator of antioxidant genes' transcription [17]. In macrophages treated with ethanol- or lipopolysaccharides (LPS), SE FAE suppresses the ethanol- and LPS-stimulated transcription of glutamate-cysteine ligase, glutathione peroxidase and nuclear factor kappa B (NFKB) $[9,18]$. Acetone extracts, hydrophilic and anthocyanin-rich fractions of SE fruits possessing high in-vitro antioxidant activity protect macrophages from the oxidative stress-mediated cytotoxicity caused by tert-Butyl hydroperoxide [19]. Ethyl acetate fraction of SE fruits possesses cytoprotective and anti-inflammatory activity reducing ethanol-induced cell death, proinflammatory gene transcription in macrophages [9]. Methanolic extracts of SE fruits reduce carrageenan-induced paw edema in rats [20]. Others describe the antiemetic, neuroprotective and anti-herpes-simplex-virus activities of SE fruit extracts [12,21].

In an intervention study on healthy adult volunteers, SE fruit tea enhances serum antioxidant potential, improves lipid profile [22], decreases serum CRP, IL-1 $\beta$, leptin and adiponectin levels [23], thus indicating an immune- and fat metabolism-modulating activity. A clinical trial reported the effectiveness of SE fruit ethanol extract for the treatment of paederus dermatitis, proving its anti-inflammatory and wound healing potential [24].

LPS-stimulated macrophages are widely used in-vitro models for testing antiinflammatory activity of medicinal plant extracts. The macrophages are source of a variety of pro-inflammatory cytokines, chemokines, and may act in a paracrine and endocrine mode. In low grade inflammation, such as in adiposity, where the activation of chemokine release is associated with macrophage recruitment and unlocking a self-feeding inflammatory process that leads to such complications as insulin resistance and related atherosclerosis [25]. The released cytokines and chemokines, such as TNF $\alpha$, IL-6, IL-1 $\beta$, NO, as a product of iNOS, activate signaling pathways mediated by Jun N-terminal kinase (JNK), the inhibitor of $\kappa B$-kinase (IKK) $\beta$ and other serine kinases [25-28], and resulting in NFKB activation. The latter stimulates the transcription of pro-inflammatory genes [29].

Along with the protein synthesis, endoplasmic reticulum (ER) plays an important role in sensing nutrients and responds to different stress conditions by activating the unfolded protein response and subsequently implicating it into insulin resistance and cardiovascular diseases [30,31]. ER stress can promote inflammation, and vice versa [32,33]. ER stressrelated inflammation could be mediated by iNOS [34]. Therefore, the enzyme iNOS as a cross point of inflammation and ER stress could be a possible therapeutic target.

There are data that ER stress and inflammation in different pathological conditions could be reduced by compounds such as resveratrol [35,36], epigallocatechin gallate [37] and proanthocyanidins found in herbal extracts [38]. SE fruits, being rich polyphenolics, anthocyanins and stilbenes, could be effective in combating ER stress and inflammation. 
We aimed to analyze the phytochemical composition of SE FAE and to test its immuneand ER stress-modulating potential in a model of unstimulated and LPS-challenged J774A.1 mouse macrophages. The phytochemical analysis of SE FAE revealed the presence of numerous compounds with anti-inflammatory and ER stress-reducing activity. For first time it was established that the transcription-modulating effect of SE FAE on inflammatory cytokines, chemokines, and enzymes in non-stimulated macrophages. In LPS-challenged macrophages, SE FAE suppresses the translation of iNOS and ER stress-related proteins.

\section{Results}

\subsection{Phytochemical Content and Composition}

Among the phytochemical compounds identified in the tested SE FAE 15 amino acids (AAs), 10 organic acids (OAs), 36 sugar acids and alcohols, 25 mono-, di- and trisaccharides, 13 fatty acids (saturated and unsaturated) and their esters (Table 1), and 38 phenolic compounds were detected and quantified (Table 2).

Table 1. List of polar phytochemicals identified in the analyzed polar fraction (A) of SE FAE using GC-MS technique. The concentration was given in $\mu \mathrm{g} / \mathrm{mL}$ extract. Results are presented as mean \pm standard deviation.

\begin{tabular}{|c|c|}
\hline Compound & Content, $\mu \mathrm{g} / \mathrm{mL}$ \\
\hline \multicolumn{2}{|c|}{ Amino Acids } \\
\hline L-Valine & $3.02 \pm 0.21$ \\
\hline L-Leucine & $8.06 \pm 0.56$ \\
\hline L-Isoleucine & $8.48 \pm 0.59$ \\
\hline L-Proline & $20.01 \pm 1.40$ \\
\hline L-Threonine & $3.89 \pm 0.27$ \\
\hline L-Phenylalanine & $10.25 \pm 0.72$ \\
\hline L-Lysine & $4.37 \pm 0.31$ \\
\hline Glycine & $3.78 \pm 0.26$ \\
\hline Serine & $2.59 \pm 0.18$ \\
\hline L-Aspartic acid & $16.32 \pm 1.14$ \\
\hline L-Asparagine & $6.19 \pm 0.43$ \\
\hline L-Glutamic acid & $1.34 \pm 0.09$ \\
\hline L-Glutamine & $22.99 \pm 1.61$ \\
\hline DL-Ornithine & $12.36 \pm 0.86$ \\
\hline L-Tyrosine & $2.66 \pm 0.19$ \\
\hline \multicolumn{2}{|c|}{ Organic Acids } \\
\hline Succinic acid & $12.64 \pm 0.88$ \\
\hline Fumaric acid & $6.61 \pm 0.46$ \\
\hline Malic acid & $9.22 \pm 0.65$ \\
\hline Pyroglutamic acid (5-oxoproline) & $33.63 \pm 2.35$ \\
\hline 4-Aminobutyric acid & $5.69 \pm 0.40$ \\
\hline 2-Hydroxyglutaric acid & $4.07 \pm 0.29$ \\
\hline 2-Ketoglutaric acid & $8.02 \pm 0.56$ \\
\hline Phenylpyruvic acid & $2.18 \pm 0.15$ \\
\hline 2,3-Dihydroxybutanedioic acid & $10.49 \pm 0.73$ \\
\hline Isocitric acid & $18.12 \pm 1.27$ \\
\hline \multicolumn{2}{|c|}{ Sugar Acids and Alcohols } \\
\hline Glycerol & $36.12 \pm 2.53$ \\
\hline Digalactosylglycerol & $6.99 \pm 0.63$ \\
\hline Glyceric acid & $17.05 \pm 1.19$ \\
\hline Threitol & $7.66 \pm 0.54$ \\
\hline Erythreol & $2.09 \pm 0.15$ \\
\hline Erithreonic acid & $2.65 \pm 0.19$ \\
\hline Threonic acid & $8.40 \pm 0.59$ \\
\hline
\end{tabular}


Table 1. Cont.

\begin{tabular}{|c|c|}
\hline Compound & Content, $\mu \mathrm{g} / \mathrm{mL}$ \\
\hline \multicolumn{2}{|l|}{ Sugar Acids and Alcohols } \\
\hline Xylitol & $4.20 \pm 0.29$ \\
\hline Arabinitol & $34.65 \pm 2.43$ \\
\hline Pentonic acid & $7.69 \pm 0.54$ \\
\hline L-Glycerol-3-phosphate & $17.72 \pm 1.24$ \\
\hline Ribonic acid & $4.76 \pm 0.33$ \\
\hline Manitol & $2.98 \pm 0.21$ \\
\hline Sorbitol & $49.26 \pm 3.45$ \\
\hline Glucuronic acid isomer & $8.49 \pm 0.59$ \\
\hline Galactitol & $1.91 \pm 0.13$ \\
\hline Galacturonic acid isomer & $15.91 \pm 1.11$ \\
\hline Glucuronic acid isomer & $13.03 \pm 0.91$ \\
\hline Gluconic acid isomer & $1.78 \pm 0.12$ \\
\hline Galacturonic acid isomer & $2.89 \pm 0.20$ \\
\hline Glucuronic acid isomer & $3.87 \pm 0.27$ \\
\hline Galactonic acid & $6.33 \pm 0.44$ \\
\hline Gluconic acid isomer & $3.71 \pm 0.26$ \\
\hline Glucaric acid & $14.00 \pm 0.98$ \\
\hline Galactaric acid & $3.38 \pm 0.24$ \\
\hline Myo-inositol & $6.71 \pm 0.47$ \\
\hline Galactosylglycerol & $22.50 \pm 1.58$ \\
\hline Sorbitol-6-phosphate & $43.32 \pm 3.03$ \\
\hline myo-Inositol-1-phosphate isomer & $5.64 \pm 0.39$ \\
\hline myo-Inositol-2-phosphate isomer & $7.43 \pm 0.52$ \\
\hline Gluconic acid-6-phosphate & $1.54 \pm 0.11$ \\
\hline myo-Inositol-1-phosphate isomer & $3.30 \pm 0.23$ \\
\hline myo-Inositol-2-phosphate isomer & $6.87 \pm 0.48$ \\
\hline Maltitol; alpha-D-Glc-(1,4)-D-sorbitol & $4.90 \pm 0.34$ \\
\hline Galactinol isomer; alpha-D-Gal-(1,3)-myo-Inositol & $0.69 \pm 0.05$ \\
\hline Galactinol isomer; alpha-D-Gal-(1,3)-myo-Inositol & $3.67 \pm 0.26$ \\
\hline \multicolumn{2}{|l|}{ Saccharides (mono-, di-, and tri-) } \\
\hline Xylose methoxyamine & $5.94 \pm 0.42$ \\
\hline Arabinose methoxyamine & $12.65 \pm 0.89$ \\
\hline Fructose isomer & $14.31 \pm 1.00$ \\
\hline Fructose isomer & $18.89 \pm 1.32$ \\
\hline Sorbose isomer & $28.11 \pm 1.97$ \\
\hline Sorbose isomer & $21.35 \pm 1.49$ \\
\hline Galactose isomer & $35.19 \pm 2.46$ \\
\hline Galactose isomer & $13.86 \pm 0.97$ \\
\hline Glucose isomer & $17.34 \pm 1.21$ \\
\hline Glucose isomer & $13.59 \pm 0.95$ \\
\hline Fructose-6-phosphate isomer & $16.20 \pm 1.13$ \\
\hline Mannose-6-phosphate isomer & $3.47 \pm 0.24$ \\
\hline Galactose-6-phosphate isomer & $18.79 \pm 1.32$ \\
\hline Glucose-6-phosphate isomer & $30.27 \pm 2.12$ \\
\hline Fructose-6-phosphate isomer & $5.81 \pm 0.41$ \\
\hline Galactose-6-phosphate isomer & $3.32 \pm 0.23$ \\
\hline Glucose-6-phosphate isomer & $4.52 \pm 0.32$ \\
\hline Sucrose; alpha-D-Glc-(1,2)-beta-D-Fru isomer & $24.81 \pm 1.74$ \\
\hline Trehalose; alpha-D-Glc-(1,1)-alpha-D-Glc isomer & $10.10 \pm 0.71$ \\
\hline Melibiose isomer; alpha-D-Gal-(1,6)-D-Glc isomer & $18.59 \pm 1.30$ \\
\hline Melibiose isomer; alpha-D-Gal-(1,6)-D-Glc isomer & $18.80 \pm 1.32$ \\
\hline Sucrose; alpha-D-Glc-(1,2)-beta-D-Fru isomer & $20.55 \pm 1.44$ \\
\hline Trehalose; alpha-D-Glc-(1,1)-alpha-D-Glc isomer & $16.13 \pm 1.13$ \\
\hline Raffinose; alpha-D-Gal-(1,6)-alpha-D-Glc-(1,2)-beta-D-Fru isomer & $12.91 \pm 0.90$ \\
\hline Raffinose; alpha-D-Gal-(1,6)-alpha-D-Glc-(1,2)-beta-D-Fru isomer & $25.61 \pm 1.79$ \\
\hline
\end{tabular}


Table 1. Cont.

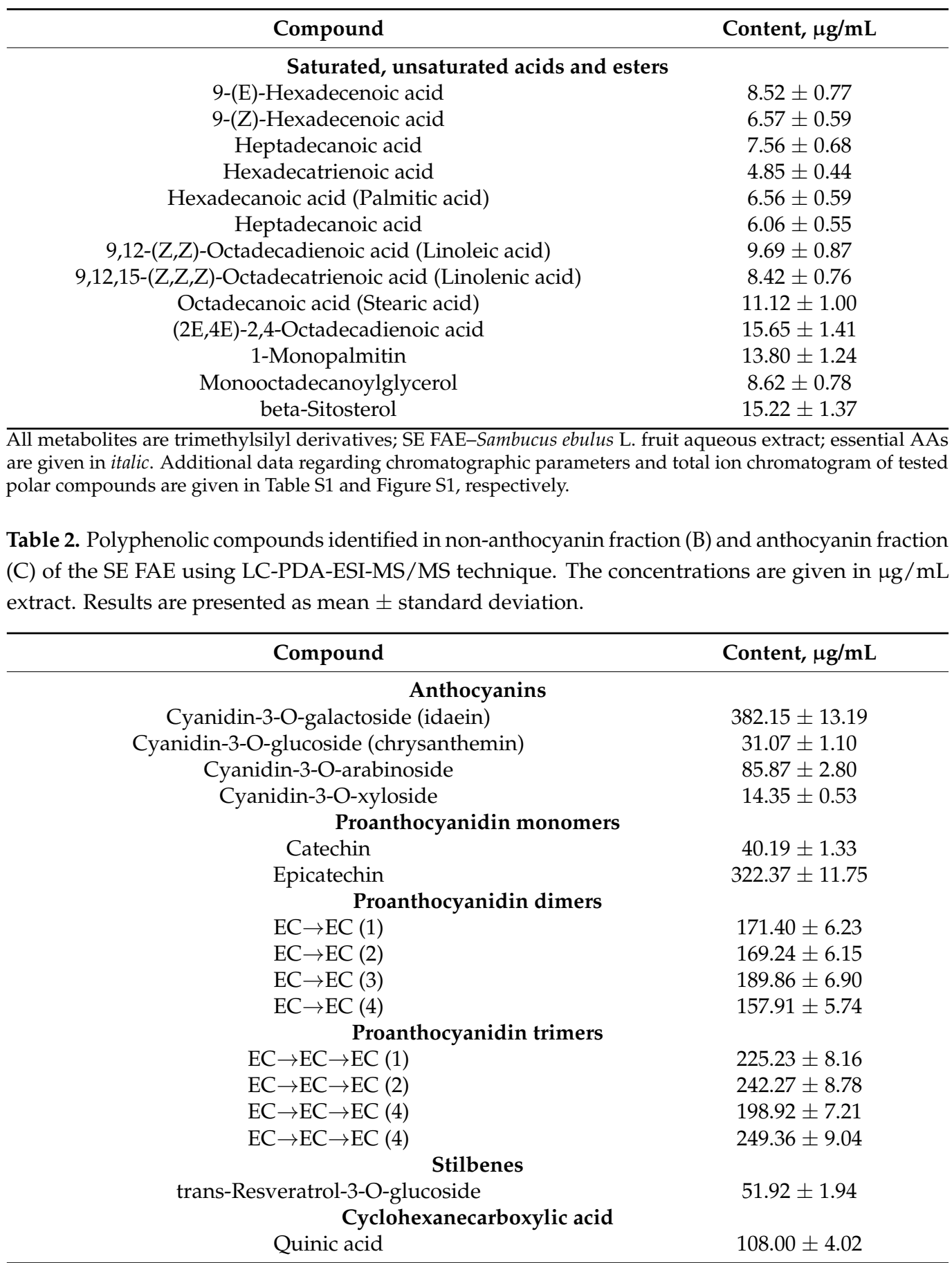


Table 2. Cont.

\begin{tabular}{cc}
\hline Compound & Content, $\mu \mathrm{g} / \mathrm{mL}$ \\
\hline Hydroxycinnamic acids & \\
3-O-Caffeoylquinic acid (chlorogenic acid) & $567.06 \pm 20.55$ \\
Caffeic acid-O-galactoside & $98.72 \pm 3.58$ \\
Caffeic acid-O-glucoside & $74.66 \pm 2.71$ \\
5-O-Caffeoylquinic acid (neochlorogenic acid) & $906.08 \pm 32.84$ \\
p-Coumaric acid-O-glucoside & $236.37 \pm 8.57$ \\
3-O-p-Coumaroylquinic acid & $399.47 \pm 14.48$ \\
Feruloylquinic acid & $248.93 \pm 9.02$ \\
4-O-p-Coumaroylquinic acid & $219.83 \pm 7.97$ \\
Ferulic acid-O-galactoside & $131.66 \pm 4.77$ \\
Ferulic acid-O-glucoside & $122.26 \pm 4.43$ \\
Flavonol glycosides & \\
Quercetin-3-O-rhamnosyl-galactoside & $25.57 \pm 0.93$ \\
Quercetin-3-O-galactoside (hyperoside) & $29.17 \pm 1.06$ \\
Kaempferol-3-O-galactoside & $11.15 \pm 0.40$ \\
Quercetin-3-O-rhamnosyl-glucoside & $20.35 \pm 0.74$ \\
Quercetin-3-O-glucoside (isoquercetin) & $22.80 \pm 0.83$ \\
Kaempferol-3-O-glucoside (astragalin) & $9.94 \pm 0.36$ \\
Quercetin-3-O-arabinoside (guaiaverin) & $16.77 \pm 0.61$ \\
Quercetin-3-O-xyloside & $13.97 \pm 0.51$ \\
Kaempferol-3-O-rhamnosyl-galactoside & $12.52 \pm 0.45$ \\
Kaempferol-3-O-rhamnosyl-glucoside & $9.15 \pm 0.33$ \\
Kaempferol-3-O-arabinoside & $11.15 \pm 0.40$ \\
Kaempferol-3-O-xyloside & $12.80 \pm 0.46$ \\
Total analyzed polyphenols & 5840.50 \\
\hline
\end{tabular}

EC-epicatechin; SE FAE-Sambucus ebulus L. fruit aqueous extract. Additional data regarding precursor ion and fragment ion mass-to-charge ratios $(\mathrm{m} / \mathrm{z})$ of the analyzed polyphenols are given in Table S2. Representative LC-PDA-ESI-MS/MS chromatograms of detected polyphenols are given in Figure S2 (anthocyanins), Figure S3 (proanthocyanidin monomers), Figure S4 (proanthocyanidin proanthocyanidin di- and trimers), Figure S5 (stilbenes), Figure S6 (hydroxycinnamic acids), Figure S7 (hydroxycinnamic acids), Figures S8-S11 (flavonols).

\subsubsection{Polar Compounds}

The most abundant AAs were L-glutamine (18.20\% of AAs content) followed by Lproline (15.84\% of AAs), L-aspartic acid (12.92\% of AAs), DL-ornithine (9.78\% of AAs). Six of all fifteen identified AAs were essential (Val, Leu, Ile, Thr, Phe and Lys). Among them phenylalanine was found to be in highest concentration $(10.25 \pm 0.75 \mu \mathrm{g} / \mathrm{mL})$, followed by isoleucine $(8.48 \pm 0.49 \mu \mathrm{g} / \mathrm{mL})$ and leucine $(8.06 \pm 0.56 \mu \mathrm{g} / \mathrm{mL})$ (Table 1). All essential AA comprise $30 \%$ of all detected AA content in SE extract.

Among the identified polar OAs, pyroglutamic acid (30.39\% of OAs content) and isocitric acid ( $16.37 \%$ of OAs) are found to be in highest concentrations (Table 1). Sorbitol and its 6-phosphate are pre-dominant $(92.58 \pm 3.24 \mu \mathrm{g} / \mathrm{mL}, 34.47 \%$ of alcohols) alcohols in the SE FAE, followed by glycerol and its 3-phosphate $(60.84 \pm 3.35 \mu \mathrm{g} / \mathrm{mL}, 22.65 \%$ of alcohols) and arabinitol (34.65 $\pm 2.43 \mu \mathrm{g} / \mathrm{mL}, 12.90 \%$ of alcohols). Glucuronic and galacturonic acid isomers and glyceric acid were among the prevailing sugar acids (Table 1).

Dominating saccharides were galactose and its 6-phosphate form $(57.30 \mu \mathrm{g} / \mathrm{mL})$, followed by glucose and its 6-phosphate form $(52.13 \mu \mathrm{g} / \mathrm{mL})$ and sorbose $(49.46 \mu \mathrm{g} / \mathrm{mL})$. Sucrose $(45.36 \mu \mathrm{g} / \mathrm{mL})$ was the prevailing disaccharide in the extract. In total, the amount of saccharides was $411.11 \mu \mathrm{g} / \mathrm{mL}$ (Table 1 ).

Among the tested fatty acids and fatty esters, we found the highest concentration for octadecadienoic acid $(15.65 \pm 1.41 \mu \mathrm{g} / \mathrm{mL}, 18.41 \%$ of fatty acids) and for beta-sitosterol $(15.22 \pm 1.37 \mu \mathrm{g} / \mathrm{mL}, 40.43 \%$ of esters and sterols) (Table 1$)$. 


\subsubsection{Polyphenolic Content}

S. ebulus L. fruits are a rich source of polyphenolics especially anthocyanins, proanthocyanidins and phenolic acids (Table 2). Cyanidin-3-O-galactoside $(382.15 \mu \mathrm{g} / \mathrm{mL}, 74.43 \%$ of anthocyanins) was at highest concentration among anthocyanins and epicatechin was the major proanthocyanidin $(322.37 \mu \mathrm{g} / \mathrm{mL})$. Among proanthocyanidin polymers dominate epicatechin dimers $(688.42 \mu \mathrm{g} / \mathrm{mL})$ and trimers $(915.79 \mu \mathrm{g} / \mathrm{mL})$ comprising $11.79 \%$ and $15.68 \%$, respectively, of all detected polyphenolics in our samples. All together anthocyanins and proanthocyanidins were $1966.76 \mu \mathrm{g} / \mathrm{mL}$ representing $33.67 \%$ of all analyzed polyphenols. Trans-Resveratrol-3-O-glucoside $(51.93 \mu \mathrm{g} / \mathrm{mL})$ was the only detected stilbene. Dominating hydroxycinnamic acids found in S. ebulus fruits are neochlorogenic and chlorogenic acid, followed by 3-O-p-coumaroylquinic acid and feruloylquinic acid. In total, the amount of hydroxycinnamic acids in the tested SE extract was $3005.02 \mu \mathrm{g} / \mathrm{mL}$ ( $300.5 \mathrm{mg} / \mathrm{g} \mathrm{DW}$ ) and represented $51.45 \%$ of all detected polyphenols. Hyperoside was one the major flavonol detected in our samples.

\subsection{Investigation of Inflammation Related Biomarkers in a Model of LPS-Stimulated J774A.1 Macrophages}

Aiming to study the anti-inflammatory action of the aqueous extract of dwarf elderberry under conditions of LPS-stimulated inflammatory response in J774A.1 mouse macrophages, the transcriptional levels of genes coding for proteins mediating and involved in the inflammatory process as well as the translation levels of iNOS were analyzed. Macrophage cells were pre-treated with increasing concentrations of $2.5 \%, 5 \%$ and $10 \% \mathrm{v} / \mathrm{v}$ $(0.25 \mathrm{mg} \mathrm{DW} / \mathrm{mL}, 0.5 \mathrm{mg} \mathrm{DW} / \mathrm{mL}, 1 \mathrm{mg} \mathrm{DW} / \mathrm{mL}$ respectively) SE FAE or salicylic acid (SA) for $24 \mathrm{~h}$ followed by LPS stimulation for an additional $24 \mathrm{~h}$, and included respective control treatments. It was previously reported that the concentrations of extract used in recent experiment are non-toxic for the J774A.1 cell line [18]. The analyzed genes included interleukin 1 beta $(I L-1 \beta)$, interleukin 6 (IL-6), tumor necrosis factor alpha (TNF $\alpha)$, monocyte chemoattractant protein-1 ( $M C P-1$, chemokine nomenclature: $\mathrm{C}-\mathrm{C}$ motif chemokine ligand 2 (Ccl2)), intercellular adhesion molecule-1 (Icam1), fatty acid binding protein 4 (Fabp4, adipocyte protein $2(a P 2)$, prostaglandin-endoperoxide synthase 2 (Ptgs2, cyclooxygenase-2 (COX2)), inducible NO synthase (iNOS), NADPH oxidase organizer 1 (Noxo1), interleukin 1 beta receptor antagonist (IL-1ra) and sirtuin 1 (Sirt-1). The intracellular iNOS protein levels were analyzed as well.

\subsubsection{The Effect of LPS-Stimulation on Inflammation Related Biomarkers in J774A.1 Macrophages}

As an inflammatory agent, LPS increased transcription levels of $I L-1 \beta, I L-6, T N F \alpha$, Ccl2, Icam1 and Fabp4 by fold-changes of $182(p<0.001), 27(p<0.001), 6(p<0.001), 14.9$ $(p<0.001), 7(p<0.01)$ and $1.9(p<0.001)$, respectively (Figures $1 \mathrm{a}-\mathrm{c}$ and $2 \mathrm{a}-\mathrm{c})$. Similarly, LPS-stimulated transcription of COX2, iNOS, and of Noxo1 by $18(p<0.001), 18(p<0.001)$, $3.4(p<0.05)$ folds, respectively, and of iNOS protein levels as well by $11.7(p<0.01)$ folds (Figure 3a-d). Concerning anti-inflammatory genes' expression, we observed a 12$(p<0.001)$ and 5-fold $(p<0.01)$ increase for IL-1ra and Sirt-1, respectively (Figure 4a,b). 
(a)

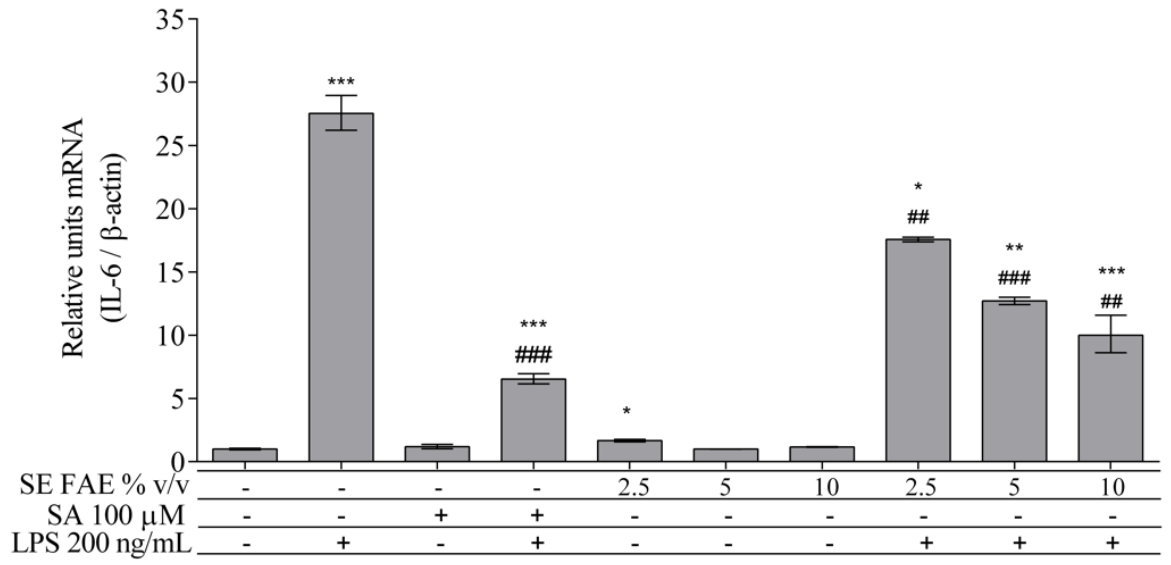

(b)

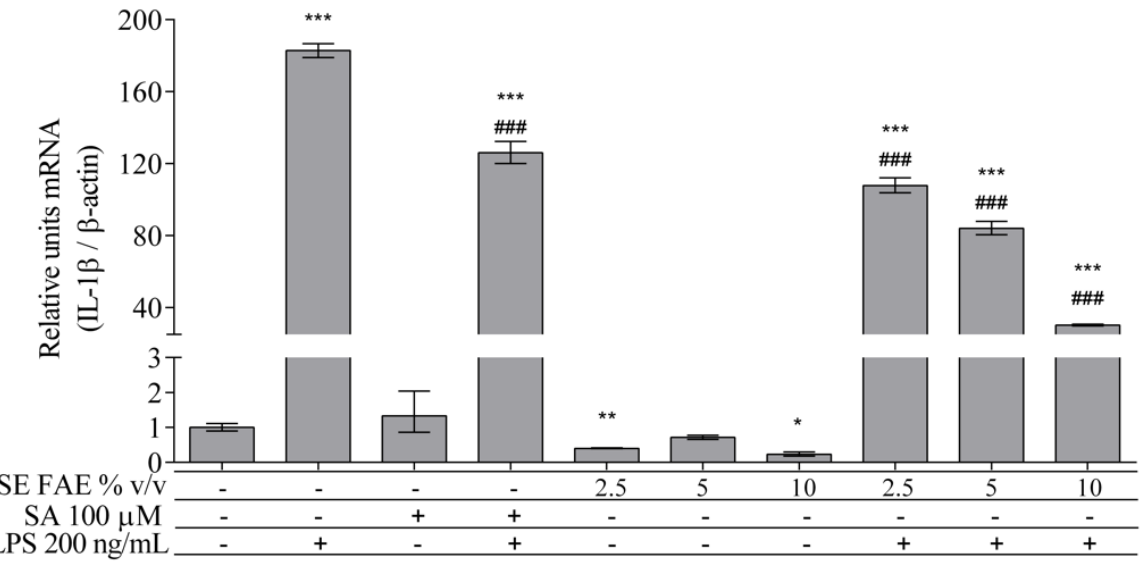

(c)

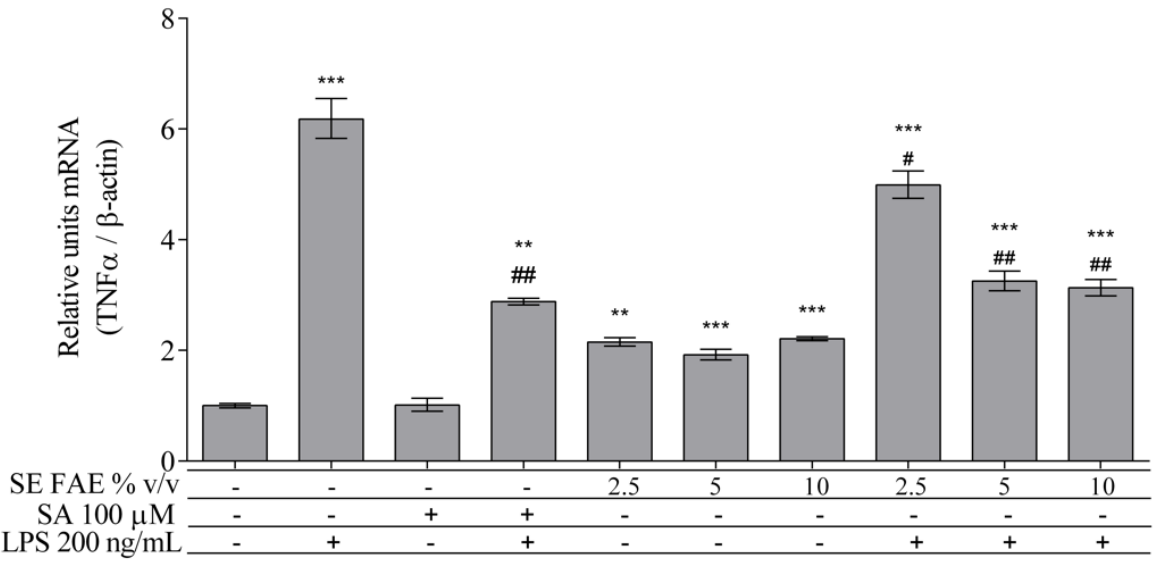

Figure 1. Changes in mRNA levels of $I L-1 \beta(\mathbf{a}), I L-6(\mathbf{b})$, and TNF $\alpha(\mathbf{c})$ in J774A.1 mouse macrophages pre-treated with increasing concentrations $(2.5 \%, 5 \%, 10 \% v / v)$ of SE FAE or with SA for $24 \mathrm{~h}$ and subsequently stimulated or not with LPS. Results were obtained using qPCR technique. Data are presented as mean \pm SEM. Legend: SE FAE-Sambucus ebulus L. fruit aqueous extract; SA-100 $\mu \mathrm{M}$ salicylic acid; LPS-200 ng/mL lipopolysaccharides. ${ }^{*} p<0.05,{ }^{* *} p<0.01,{ }^{* * *} p<0.001$ vs. untreated cells; \# $p<0.05$, \#\# $p<0.01$, \#\#\# $p<0.001$ vs. LPS. 
(a)

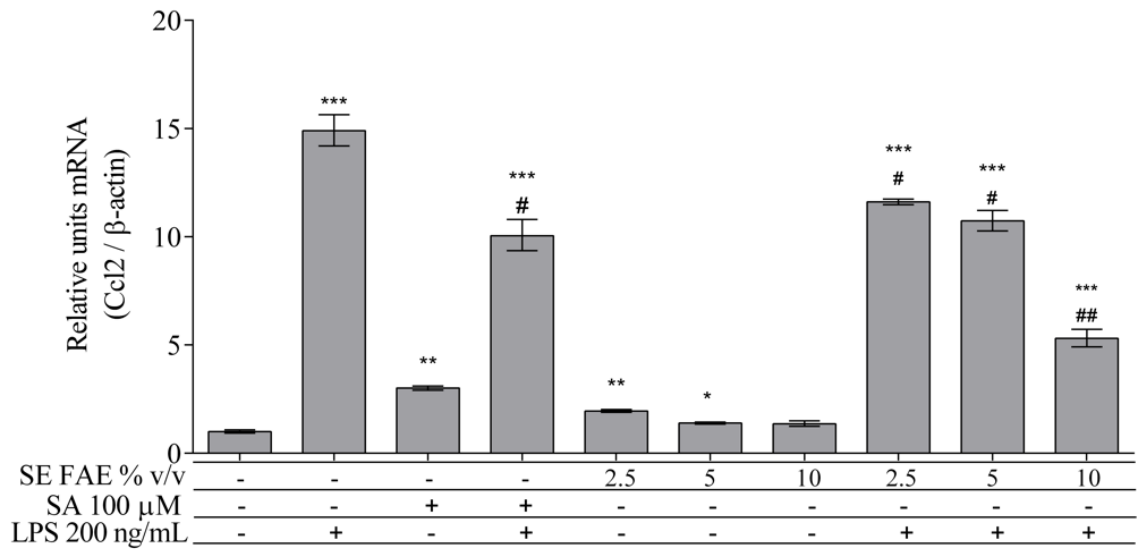

(b)

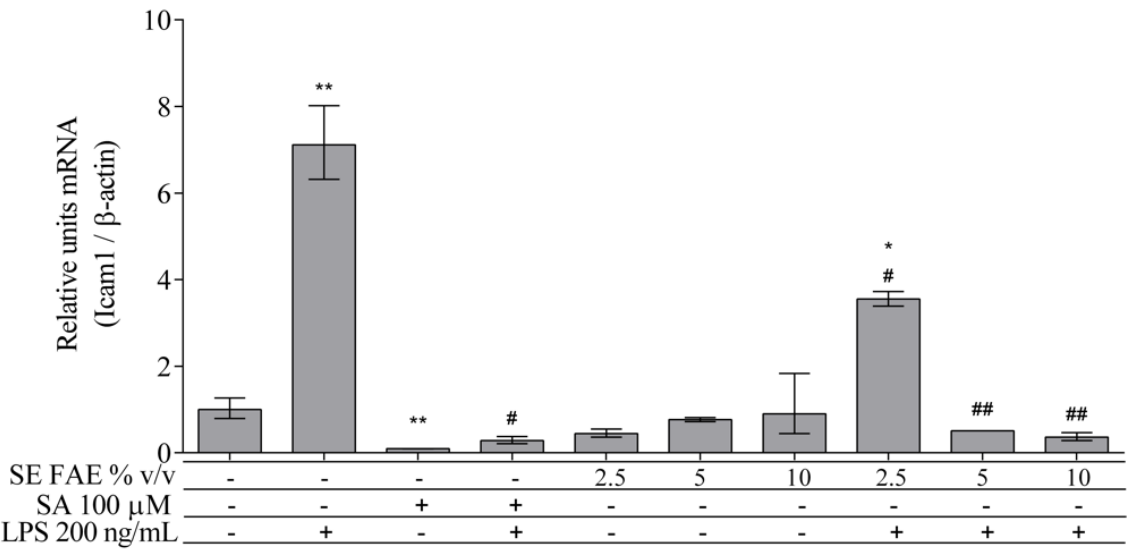

(c) $\mathrm{SA} 100 \mu \mathrm{M}$

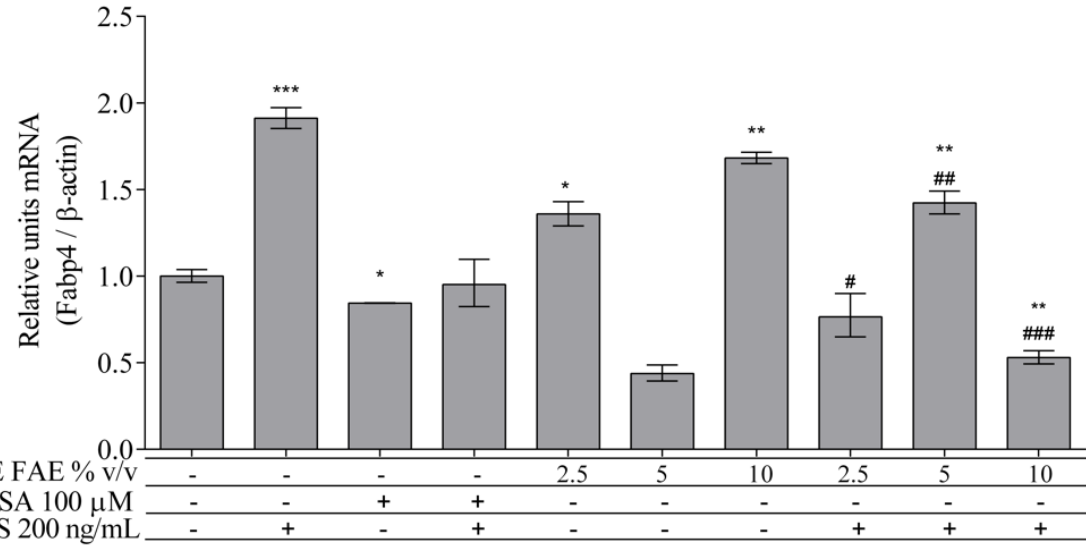

Figure 2. Changes in mRNA levels of Ccl2 (a), Icam1 (b), and Fabp4 (c) in J774A.1 mouse macrophages pre-treated with increasing concentrations $(2.5 \%, 5 \%, 10 \% v / v)$ of SE FAE or with SA for $24 \mathrm{~h}$ and subsequently stimulated or not with LPS. Results were obtained using qPCR technique. Data are presented as mean \pm SEM. Legend: SE FAE-Sambucus ebulus L. fruit aqueous extract; SA-100 $\mu \mathrm{M}$ salicylic acid; LPS-200 ng/mL lipopolysaccharides. ${ }^{*} p<0.05,{ }^{* *} p<0.01,{ }^{* * *} p<0.001$ vs. untreated cells; \# $p<0.05$, \#\# $p<0.01$, \#\# $p<0.001$ vs. LPS. 
(a)

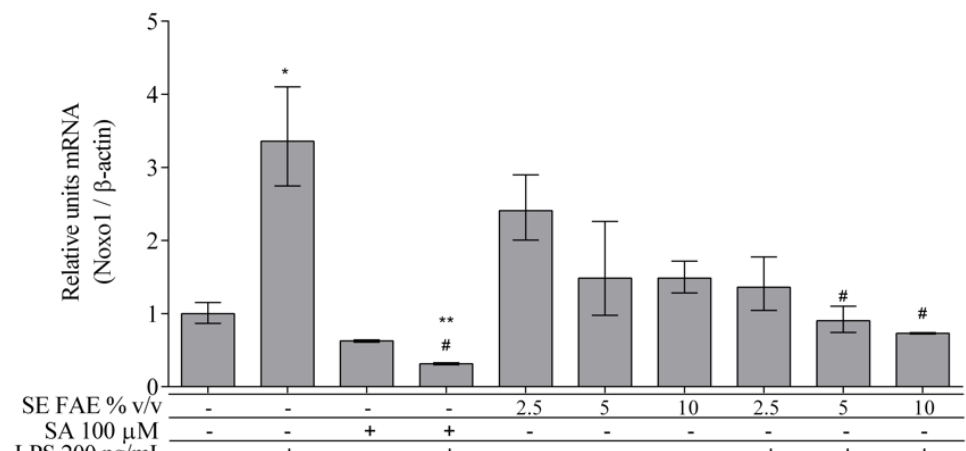

(b)

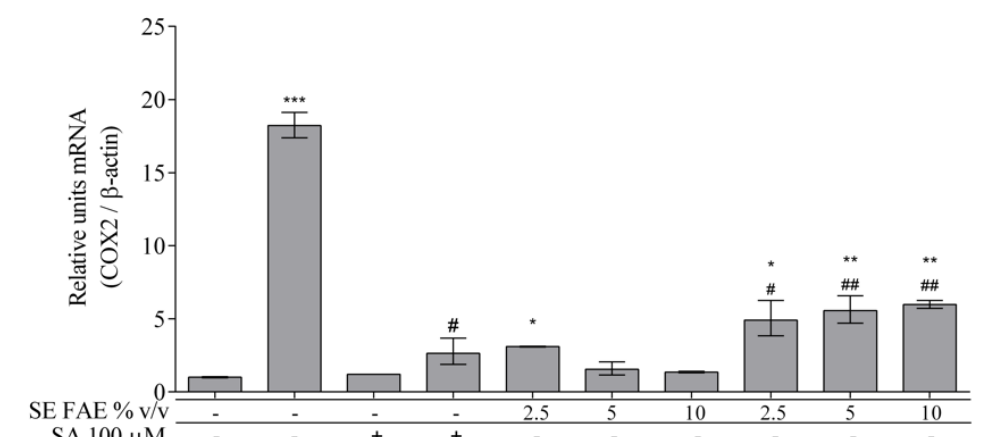

SA $100 \mu$

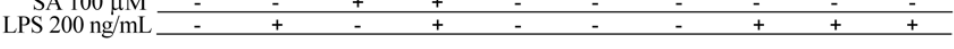

(c)

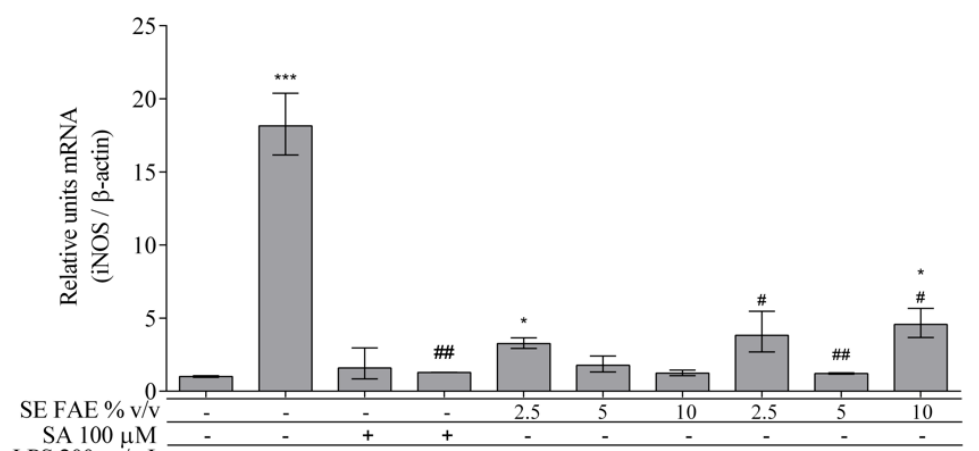

SA $100 \mu \mathrm{M}$
LPS $200 \mathrm{ng} / \mathrm{mL}$

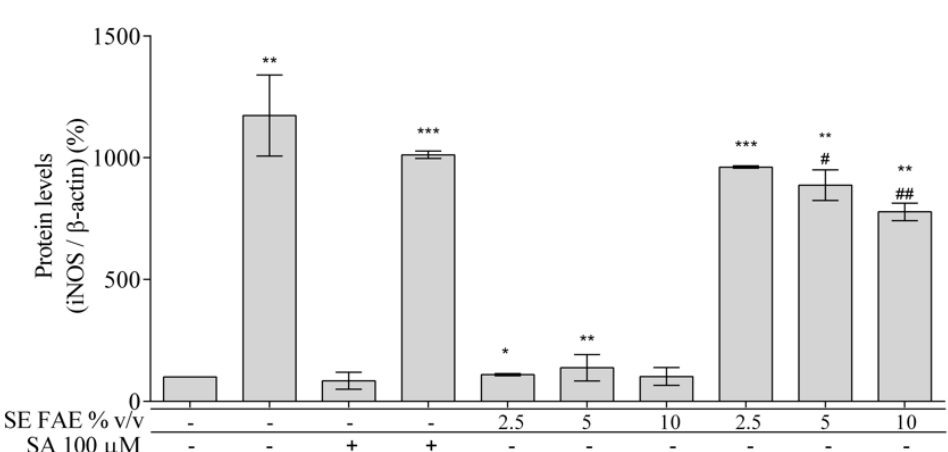

(d)

SA $100 \mu \mathrm{M}$

LPS $200 \mathrm{ng} / \mathrm{mL}$

Figure 3. Changes in mRNA levels of COX2 (a), iNOS (b), Noxo1 (c), and of protein levels of iNOS (d) in J774A.1 mouse macrophages pre-treated with increasing concentrations $(2.5 \%, 5 \%, 10 \% v / v)$ of SE FAE or with SA for $24 \mathrm{~h}$ and subsequently stimulated or not with LPS. Results were obtained using $\mathrm{qPCR}((\mathbf{a}),(\mathbf{b})$ and $(\mathbf{c}))$ or western blot technique (d). Data are presented as mean \pm SEM. Legend: SE FAE-Sambucus ebulus L. fruit aqueous extract; SA-100 $\mu \mathrm{M}$ salicylic acid; LPS-200 ng/mL lipopolysaccharides. ${ }^{*} p<0.05,{ }^{* *} p<0.01,{ }^{* * *} p<0.001$ vs. untreated cells; $\# p<0.05$, \#\# $p<0.01$ vs. LPS treatment. 


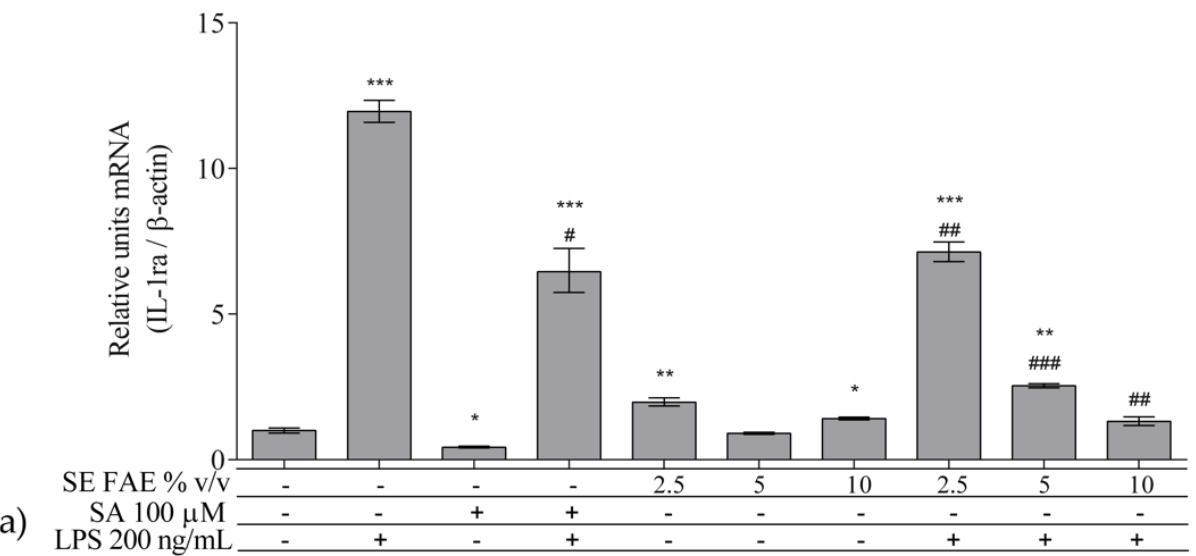

(a) LPS $200 \mathrm{ng} / \mathrm{mL}$

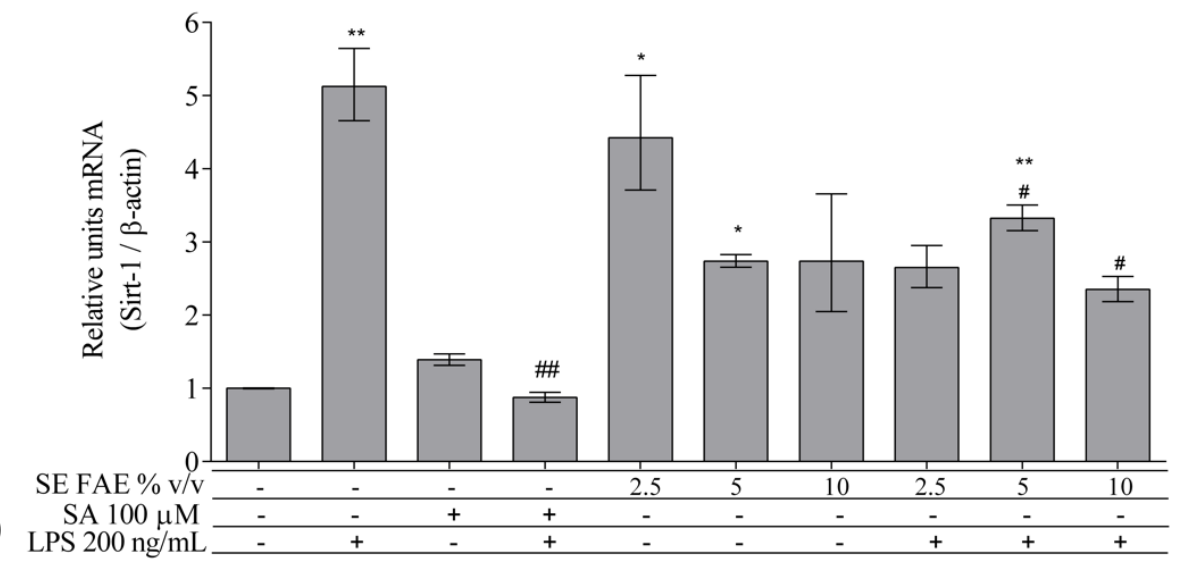

Figure 4. Changes in mRNA levels of IL-1ra (a) and of Sirt-1 (b) in J774A.1 mouse macrophages pre-treated with increasing concentrations $(2.5 \%, 5 \%, 10 \% v / v)$ of SE FAE or with SA for $24 \mathrm{~h}$ and subsequently stimulated or not with LPS. Results were obtained using qPCR technique. Data are presented as mean \pm SEM. Legend: SE FAE-Sambucus ebulus L. fruit aqueous extract; SA-100 $\mu \mathrm{M}$ salicylic acid; LPS-200 ng/mL lipopolysaccharides. ${ }^{*} p<0.05,{ }^{* *} p<0.01,{ }^{* * *} p<0.001$ vs. untreated cells; \# $p<0.05$, \#\# $p<0.01$, \#\#\# $p<0.001$ vs. LPS treatment.

\subsubsection{The Effect of SE FAE on Inflammation-Related Biomarkers in Non-Stimulated J774A.1 Macrophages}

When applied alone, 2.5\% $v / v$ and $10 \% v / v$ SE FAE slightly reduced the gene expression of $I L-1 \beta$ by $60 \%(p<0.01)$ and $77 \%(p<0.05)$, respectively, as compared to untreated cells (Figure 1a). While 2.5\% $v / v$ of herbal extract induced the gene expression of $I L-6$ (by $67 \%, p<0.05$ ), TNF $\alpha$ (by 115\%, $p<0.01$ ), Ccl2 (by 95\%, $p<0.01$ ), and Fabp4 (by $36 \%$, $p<0.05$ ) (Figures $1 \mathrm{~b}, \mathrm{c}$ and $2 \mathrm{a}, \mathrm{c})$. The higher concentration of SE FAE (5\% extract) in culture media stimulated transcription of TNF $\alpha$ (by $92 \%, p<0.001$ ) and of Ccl2 (by $39 \%, p<0.05$ ) (Figures $1 \mathrm{c}$ and $2 \mathrm{a})$, while the highest concentration (10\% extract) induced transcription of TNF $\alpha$ (by 121\%, $p<0.001$ ) and of Fabp4 (by 68\%, $p<0.01$ ) (Figures 1c and 2c). SA, applied alone, similarly to SE FAE, it enhanced transcription levels of Ccl2 (by 200\%, $p<0.01$ ), but in contrast with SE FAE, it slightly reduced those of Icam 1 (by $91 \%, p<0.01$ ) and of Fabp4 (by $16 \%, p<0.05$ ) (Figure $2 a-c$ ), while no significant effects on $I L-1 \beta, I L-6$ and TNF $\alpha$ transcription levels were observed (Figure 1a-c).

The treatment with $2.5 \% v / v$ of SE FAE alone significantly induced the transcription levels of COX2 (by 210\%, $p<0.05$ ) and of $i$ NOS (by 230\%, $p<0.05$ ) and both $2.5 \% v / v$ and $5 \% v / v$ of the extract induced iNOS protein levels by $9 \%(p<0.05)$ and by $38 \%(p<0.01)$, respectively (Figure 3). No effect of SA alone was observed on the gene expression levels of all analyzed inflammation and phagocytosis-related enzymes (Figure 3). 
SE FAE in concentrations of $2.5 \% v / v$ and $10 \% v / v$ induced the transcription levels of $I L-1 r a$ by $98 \%(p<0.01)$ and $41 \%(p<0.05)$, respectively (Figure $4 \mathrm{a})$. In contrast, SA treatment reduced IL-1ra transcription by $57 \%(p<0.05)$ (Figure $4 \mathrm{a})$. Transcription of the so-called longevity gene Sirt-1 was stimulated upon $2.5 \% v / v$ and $5 \% v / v$ SE FAE treatment by $343 \%(p<0.05)$ and by $274 \%(p<0.05)$, respectively (Figure $4 \mathrm{~b})$. There was no significant effect of SA applied alone on Sirt-1 transcription levels (Figure $4 \mathrm{~b}$ ).

2.2.3. The effect of SE FAE on Inflammation-Related Biomarkers in LPS-Stimulated J774A.1 Macrophages

In LPS-stimulated macrophages, the pre-treatment with all three increasing concentrations of SE FAE $(2.5 \% v / v, 5 \% v / v$ and $10 \% v / v)$, as compared with LPS treatment, significantly reduced the transcription levels of $I L-1 \beta, I L-6, T N F \alpha, C c l 2$, and of Icam 1 with up to $83 \%(p<0.001), 67.7 \%(p<0.01), 49 \%(p<0.01), 64 \%(p<0.01)$, and $94.9 \%(p<0.01)$, respectively (Figures $1 \mathrm{a}-\mathrm{c}$ and $2 \mathrm{a}, \mathrm{b}$ ). The effect followed a dose-dependent manner. Similarly, all concentrations reduced LPS-stimulated Fabp 4 mRNA levels, with stronger effect exerted by $2.5 \% v / v$ (by $60.2 \%, p<0.05$ ) and by $10 \% v / v$ (by $72.4 \%, p<0.001$ ) SE FAE (Figure 2c). Considering the effect of SE FAE alone on Fabp4, we may recognize that the same concentrations stimulating its gene expression $(2.5 \% v / v$ and $10 \% v / v)$ are the ones exerting the stronger reducing effect in the case of LPS-stimulated cells.

Pre-treatment with the SA as a known anti-inflammatory compound, significantly reversed the LPS stimulation of all genes except Fabp4, as follows: IL- $1 \beta(31 \%, p<0.001)$; IL-6 (76\%, $p<0.001)$; TNF $\alpha$ (53\%, $p<0.01)$; Ccl2 (32\%, $p<0.05)$; Icam1 $(96 \%, p<0.05)$ (Figures $1 \mathrm{a}-\mathrm{c}$ and $2 \mathrm{a}, \mathrm{b}$ ). The inhibitory effect of SE FAE on LPS-stimulated transcription of pro-inflammatory genes was similar to the effect of the positive control SA. In the case of Icam1, both the extract and the SA reduced the LPS-induced mRNA levels back to normal. When applied in highest concentration $(10 \% v / v)$ the herbal extract had a reducing effect on the LPS-stimulated gene expression of $I L-1 \beta, C c l 2$, and of Fabp4, which was even stronger than that of the SA.

SE FAE significantly inhibited the LPS-stimulated transcription levels of COX2, iNOS and of Noxo1, by up to $73 \%(p<0.05), 93 \%(p<0.01)$ and $78 \%(p<0.05)$, respectively, and the protein levels of iNOS by up to $33 \%(p<0.01)$ (Figure 3a-d). When SA was applied prior to LPS stimulation mRNA levels of COX2, iNOS and Noxo1 were reduced by $85 \%(p<0.05)$, $92.9 \%(p<0.01)$, and by $90.7 \%(p<0.05)$, respectively (Figure 3a-c). The effect shown by SE FAE was similar to that of SA and they both independently reduced LPS-stimulated transcription of $i N O S$ and of Noxo1 back to the normal levels. Pre-treatment with herbal extract showed a stronger iNOS mRNA- and protein levels-reducing effect than the SA did in LPS-challenged cells.

Application of SE FAE suppressed the LPS-induced transcription of IL-1ra by up to $88.95 \%(p<0.01)$ in a dose-dependent manner and that of Sirt- 1 by up to $54 \%(p<0.05)$ (Figure 4). Similar effect was observed in the SA pre-treated cells, where LPS-induced IL-1ra and Sirt-1 mRNA transcription levels were decreased by $46 \%(p<0.05)$ and by $82 \%$ $(p<0.01)$, respectively (Figure 4). SE FAE exerted stronger reducing activity than that of SA on LPS-stimulated IL-1ra transcription, decreasing it to the normal levels.

\subsection{Investigation of ER Stress-Related Biomarkers in a Model of LPS-Stimulated J744A.1 Macrophages}

Regarding the well-known relationship between inflammation and ER stress, we have analyzed intracellular protein levels of ER stress-related proteins: activating transcription factor 6 alpha (ATF6 $\alpha$ ), phosphorylated eukaryotic translation initiation factor 2 alpha (peIF $2 \alpha$ ), and their downstream target gene's product C/EBP homologous protein (CHOP, growth arrest and DNA damage-inducible gene 153 (GADD153)) in a model of LPS-stimulated J744A.1 macrophages (Figure 5). Cells were pre-treated with increasing concentrations of $2.5 \%, 5 \%$ and $10 \% v / v(0.25 \mathrm{mg} \mathrm{DW} / \mathrm{mL}, 0.5 \mathrm{mg} \mathrm{DW} / \mathrm{mL}, 1 \mathrm{mg} \mathrm{DW} / \mathrm{mL}$ respectively) SE FAE or SA for $24 \mathrm{~h}$ followed by LPS-stimulation for additional $24 \mathrm{~h}$, and respective control treatments were performed as well. 
(a)

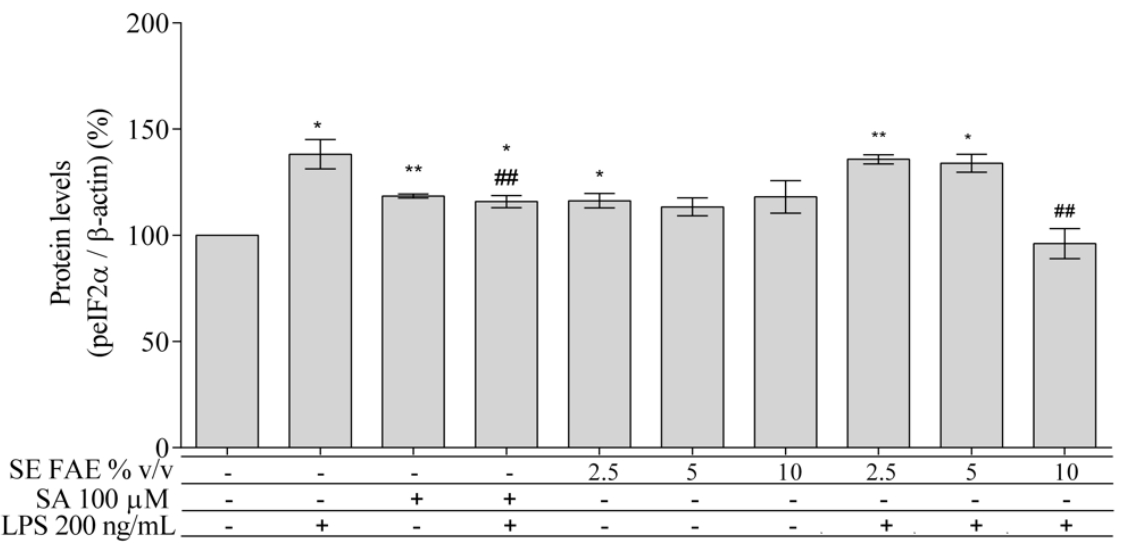

(b)

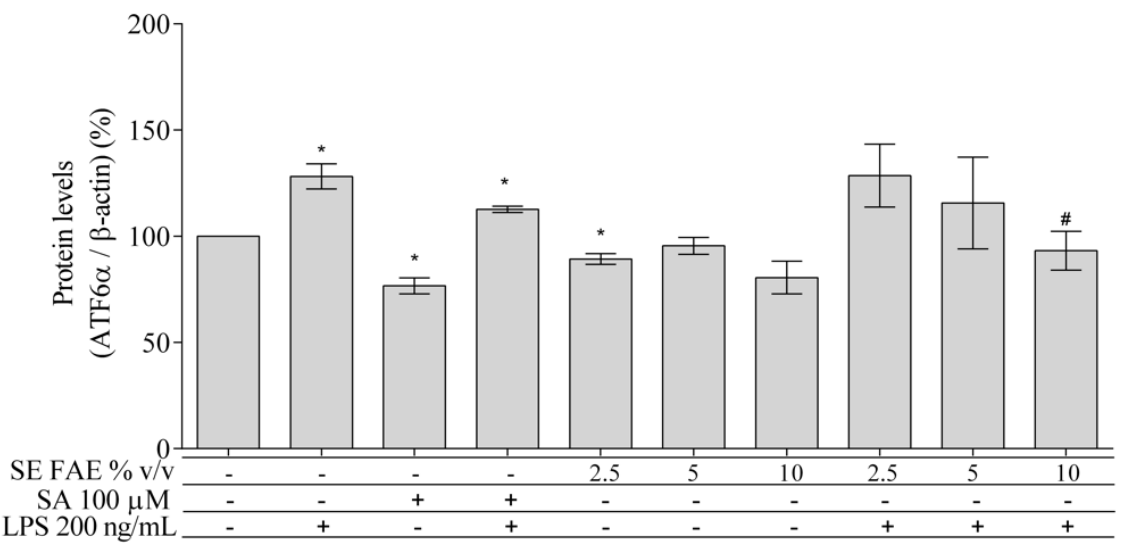

(c)

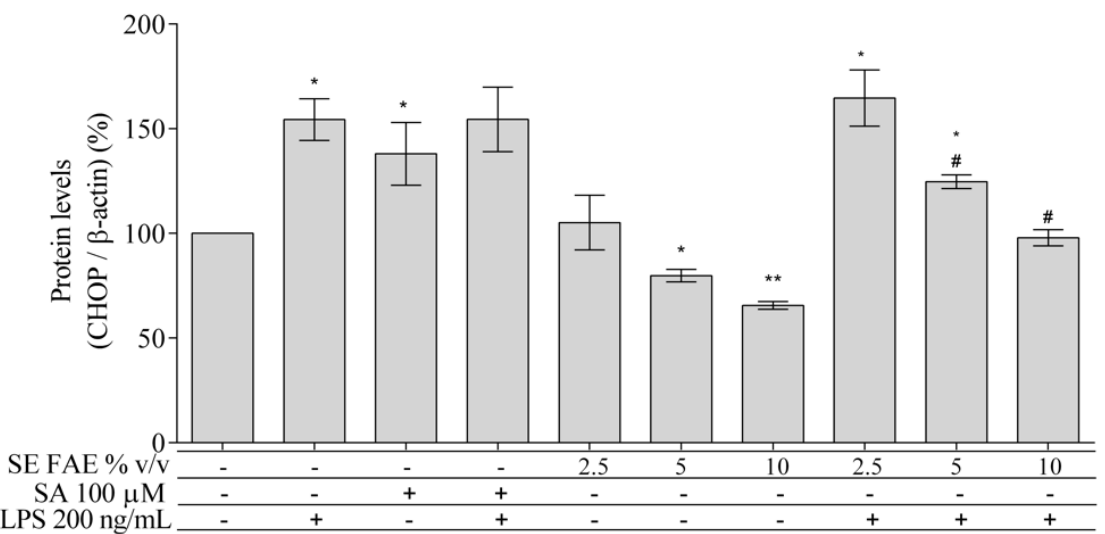

Figure 5. Changes in the protein levels of peIF2 $\alpha(\mathbf{a}), \operatorname{ATF} 6 \alpha(\mathbf{b})$, and CHOP (c) in J774A.1 mouse macrophages pre-treated with increasing concentrations $(2.5 \%, 5 \%, 10 \% v / v)$ of SE FAE or with SA for $24 \mathrm{~h}$ and subsequently stimulated or not with LPS. Results were obtained using the Western blot technique. Data are presented as mean \pm SEM. Legend: SE FAE-Sambucus ebulus L. fruit aqueous extract; SA-100 $\mu \mathrm{M}$ salicylic acid; LPS-200 ng/mL lipopolysaccharides. ${ }^{*} p<0.05,{ }^{* *} p<0.01 \mathrm{vs}$. untreated cells; \# $p<0.05$, \#\# $p<0.01$ vs. LPS treatment.

\subsubsection{The Effect of LPS-Stimulation on ER Stress-Related Biomarkers in} J774A.1 Macrophages

LPS treatment significantly induced the levels of peIF2 $\alpha$ (Figure 5a), ATF6 $\alpha$ (Figure 5b), and CHOP (Figure $5 c$ ) proteins by 38\% $(p<0.05), 28 \%(p<0.05)$, and 54\% $(p<0.05)$, respectively. 
2.3.2. The Effect of SE FAE on ER Stress-Related Biomarkers in Non-Stimulated J744A.1 Macrophages

Applied alone, SE FAE in concentration of $2.5 \% v / v$ slightly increased peIF2 $\alpha$ (by $16 \%$, $p<0.05$ ) (Figure 5a), but also slightly decreased the expression of ATF6 $\alpha$ (by 11\%, $p<0.05$ ), similarly to the effect of SA (Figure $5 b$ ). The higher concentrations of the extract, $5 \% v / v$ and $10 \% v / v$, reduced, in a dose-dependent manner CHOP levels by $20 \%(p<0.05)$ and by $34 \%(p<0.01)$, respectively (Figure $5 \mathrm{c})$. The effect of SE FAE on CHOP levels was opposite to the effect of SA in non-stimulated with LPS macrophages. 2.3.3. The effect of SE FAE on ER stress-related biomarkers in LPS-stimulated J744A.1 macrophages.

2.3.3. The Effect of SE FAE on ER Stress-Related Biomarkers in LPS-Stimulated J744A.1 Macrophages

Pre-treatment of macrophages with $10 \% \mathrm{v} / \mathrm{v}$ SE FAE significantly altered the LPSstimulated levels of peIF $2 \alpha$ (by $30 \%, p<0.01$ ), similarly to the effect of the SA (by $16 \%$, $p<0.05)$. The same concentration of the extract similarly affected the expression of ATF $6 \alpha$ (reduced by $27 \%, p<0.05$ ) (Figure $5 b$ ). Both, the $5 \% v / v$ and $10 \% v / v$ of the extract in the culture media significantly reduced in a dose-dependent manner the LPS-stimulated levels of CHOP by $19 \%(p<0.05)$ and by $36 \%$, respectively (Figure $5 c)$. LPS-stimulated ATF $6 \alpha$ and $\mathrm{CHOP}$ levels were not reduced by the pre-treatment with SA.

The original western blot gels presenting the changes in protein levels of iNOS, peIF $2 \alpha$, ATF6 $\alpha$ and CHOP in J774A.1 mouse macrophages pre-treated with increasing concentrations $(2.5 \%, 5 \%, 10 \% v / v)$ of SE FAE or with SA for $24 \mathrm{~h}$ and subsequently stimulated or not with LPS, are given in Figure S12.

\subsubsection{Correlation Analyzes of ER Stress-Related Biomarkers}

Based on the established clear and consistent dose-dependent effect of SE FAE in conditions of \pm LPS stimulation, a subsequent correlation analyzes of transcription factors peIF $2 \alpha$ and ATF6 $\alpha$ and their downstream target CHOP were performed. High positive correlations between ATF $6 \alpha$ and CHOP $(\mathrm{r}=0.83, p<0.05)$ and between peIF $2 \alpha$ and CHOP $(r=0.67, p=0.08)$ were established (Figure 6).

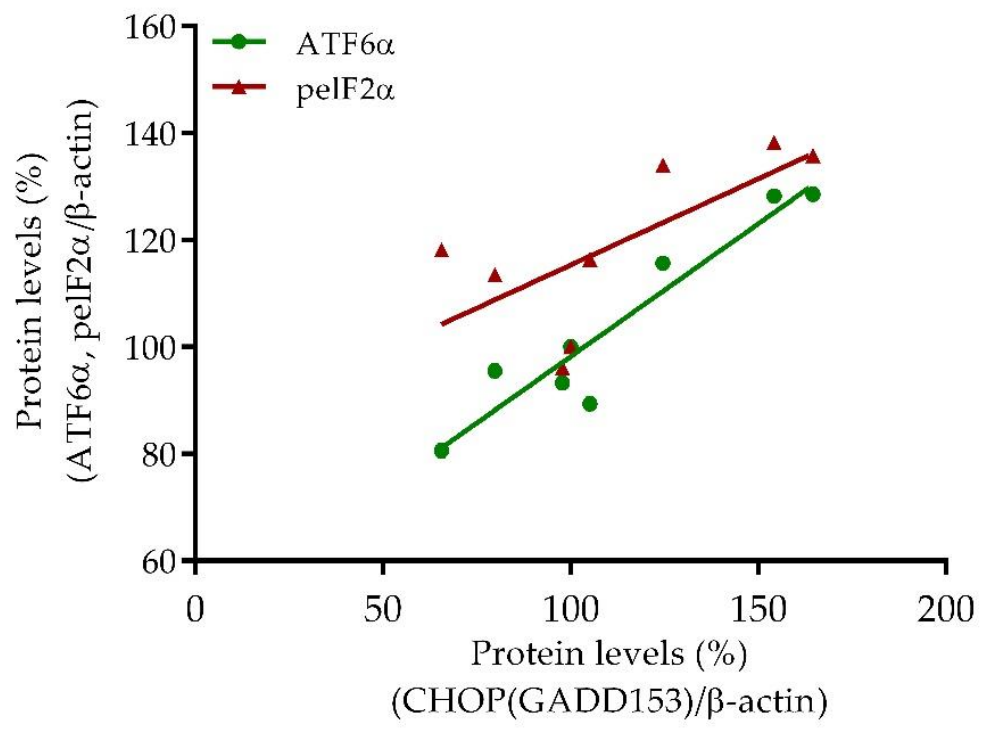

Figure 6. Correlations between protein levels of peIF2 $\alpha$ and CHOP (red triangle) and of ATF6 $\alpha$ and CHOP (green dot) in J774A.1 mouse macrophages pre-treated with increasing concentrations $(2.5 \%$, $5 \%, 10 \% v / v$ ) of SE FAE and subsequently stimulated or not with LPS. 


\section{Discussion}

\subsection{Newly Detected Phytochemicals in SE Fruit Aqueous Extract}

In the recent study we recognized as newly reported 10 AAs including 3 essential AAs, 8 OAs, 12 sugar acids and their phosphates, 16 alcohols, alcohol phosphates and their glycosides, 11 saccharides (mono-, di-, and tri-), 6 saturated and unsaturated fatty acids and 3 of their esters and 3 anthocyanins.

\subsubsection{Amino Acids}

AAs are important for building cellular proteins, nucleotides, for maintaining acidbase balance and as neurotransmitters. Especially the essential AAs are valuable food components for living organisms. Other authors have reported three essential (Val, Leu and Thr) and three non-essential AAs (Ala, Gln and Tyr) in SE extracts [13]. In our study we have identified all of them except Ala. In addition, we have found three newly detected essential AAs (Ile, Phe and Lys) and six non-essential AAs (Pro, Gly, Ser, Asp, Asn, Gln) and Orn. In total, the content of AAs in the tested SE extract was $126.30 \mu \mathrm{g} / \mathrm{mL}$, where the essential AAs comprise $30 \%$ of all AA content. Considering these findings, it could be concluded that SE fruits are a good source of both essential and non-essential AAs.

\subsubsection{Organic Acids}

The total amount of all detected OAs was $110.66 \mu \mathrm{g} / \mathrm{mL}$. We identified, for first time, seven OAs, including isocitric acid (16.37\%) and succinic acid $(11.42 \%)$, important substrates for the normal functioning of citric acid cycle and cell energy production. Fumaric and malic acid were previously reported in SE fruit extract [13]. Additionally, other authors reported the presence of citric acid in SE fruit extract, also important for energy metabolism [13]. Pyroglutamic acid (5-oxoproline) was found in the highest content (30.39\% of all OA) in our samples. Pyroglutamic acid is very important as an intermediate in $\gamma$ glutamyl cycle involved in transmembrane amino acid transportation and for synthesis of the antioxidant glutathione. We may speculate that the high content of pyroglutamic acid in our samples may be due to a high amount of its keto derivative L-proline ( $15.84 \%$ of AAs) found in SE fruits [39].

\subsubsection{Sugar Acids and Alcohols}

Regarding the content of sugar acids and sugar alcohols, the presence of pectic acid and sorbitol have been reported in the fruit of S. nigra [40,41]. Data in the literature concerning SE fruits content of sugar acids and sugar alcohols are not available.

In our study, the total amount of sugar alcohols was $268.62 \mu \mathrm{g} / \mathrm{mL}$. For first time, we identified 17 sugar alcohols and their derivatives: sorbitol and its phosphate form $(34.47 \%$ of sugar alcohols), glycerol, glycerol-3-phosphate and digalactosylglycerol (22.65\%) and arabinitol $(12.90 \%)$. Summarizing, the newly identified sugar alcohols and their derivatives comprise more than $68 \%$ of all quantified sugar alcohols in our samples. Therefore, SE fruits should be considered as a good natural source of sorbitol, glycerol and their derivatives.

The total amount of sugar acids in our samples was $115.49 \mu \mathrm{g} / \mathrm{mL}$. For the first time, 12 sugar acids were identified; of them, the highest content was found for glucuronic acid $(21.98 \%)$, galacturonic acid (16.28\%), and glyceric acid (14.76\%). Glucuronic and galacturonic acids are the most abundant sugar acids in the tested SE fruit extract, as they are the major components of plant polysaccharides, like cellulose and pectin.

\subsubsection{Saccharides}

Literature data provide information mostly about glucose and sucrose content in SE fruit extracts [13]. We report new data regarding the saccharide content of SE fruit extract: the monosaccharides comprise $64.12 \%(263.61 \mu \mathrm{g} / \mathrm{mL})$, followed by disaccharides $26.51 \%(108.98 \mu \mathrm{g} / \mathrm{mL})$, and trisaccharides (mainly raffinose) $9.37 \%(38.52 \mu \mathrm{g} / \mathrm{mL})$. Other identified monosaccharides were fructose, fructose-6-phosphate, arabinose, xylose, and mannose-6-phosphate. Disaccharides were presented by melibiose and trehalose as well. 


\subsubsection{Fatty Acids and Fatty Esters}

Data regarding the lipid composition of SE fruits are very limited. Most studies identified four sterols in SE fruit extract: brassicasterol, campesterol, stigmasterol, $\beta$ sitosterol [11,12]. In our samples, $\beta$-sitosterol $(15.22 \mu \mathrm{g} / \mathrm{mL})$ was the only sterol we detected. The newly identified fatty esters included 1-monopalmitin and monooctadecanoylglycerol. Other authors provide data regarding the presence of octadecanoic and octadecadienoic acids as well as palmitic, octadecenoic, dehydroabietic, oleic, oleanolic, ursolic, and maslinic acid [12]. We found the highest amount of any fatty acid for octadecadienoic acid $(15.65 \pm 1.41 \mu \mathrm{g} / \mathrm{mL})$ comprising $18.41 \%$ of all fatty acids $(84.98 \mu \mathrm{g} / \mathrm{mL})$, and five newly identified fatty acid (hexadecenoic, heptadecanoic, hexadecatrienoic, hexadecanoic and octadecatrienoic).

Oleanolic, ursolic, and maslinic acid are pentacyclic triterpenes known to possess anticancer properties [42,43]. Ursolic acid, particularly, reduces LPS-stimulated NFKB signaling [44], inflammatory cytokine production by inhibition JNK signaling [45], ER stress induced by high fat diet, and NFKB related inflammation [46]. It is assumed that ursolic acid may also improve insulin sensitivity $[47,48]$. In our previous study on healthy volunteers we reported that SE fruit tea intake improves lipid profiles, reducing total and LDL cholesterol serum levels and improving volunteers' HDL/LDL ratios [22]. The intake of phytosterols including $\beta$-sitosterol may reduce total serum cholesterol [49] and low-density cholesterol [50]. As brassicasterol, campesterol [11] and $\beta$-sitosterol are among the phytosterols with known cholesterol-lowering activity [51-53], it is not surprisingly that SE fruit tea exerts a cholesterol-lowering effect.

\subsubsection{Phenolic Compounds}

Compared with other species of the Sambucus genus, such as S. nigra, S. cerulea, and S. racemose, S. ebulus is the richest in total hydroxycinnamic acids, catechin, epicatechin and flavonols [15].

Anthocyanins are the predominant colored polyphenols in elderberries. In our study we identified three new anthocyanins: cyanidin-3-O-galactoside (the major anthocyanin in most plants), cyanidin-3-O-arabinoside and cyanidin-3-O-xyloside. In accordance with other studies, we also found in our samples cyanidin-3-O-glucoside, but not cyaniding-3O-sambubioside [14]. Anthocyanins exerts numerous beneficial health effects including antioxidant, anti-inflammatory, anticancer, antidiabetic, anti-toxic, cardiovascular and nerve-protective capacities [54].

Flavanols, including catechin and epicatechin, were previously reported in SE fruits $[15,16]$, as were proanthocyanidin dimers and trimers [55]. SE is the richest among the Sambucus sp. in catechins and epicatechins [15]. Epicatechin is the major proanthocyanidin monomer and a component of proanthocyanidin dimers and trimers. It is considered that one of the richest sources of proanthocyanidins are grape seeds [56]; proanthocyanidin dimer and trimer content in SE fruits is comparable to that in the grape seeds [55].

Resveratrol is the most abundant stilbene in plants. Grape peels are known as one of the best sources of resveratrol, containing on average $0.169 \mathrm{mg} / \mathrm{g}$ DW [57]. We found that trans-resveratrol-3-O-glucoside represents $5.19 \mathrm{mg} / \mathrm{g}$ DW. Thus, SE fruits and its FAE seems to be considerable sources of resveratrol. Resveratrol exerts a wide range of biological activities. It acts as calorie-restriction mimetic, increasing the levels of so-called survival protein SIRT1 and improves energy metabolism, decreases plasma glucose, triglycerides and inflammatory cytokines [58]. Its positive impacts on human heath are complemented by improved plasma antioxidant activity and reduced oxidative stress [59,60]. In obese individuals, resveratrol improves insulin sensitivity [61] and mitochondrial oxidative capacity when used in combination with epigallocatechin gallate [62].

Quinic acid is a compound conjugating with hydroxycinnamic acids to form their esters. Its presence in SE fruit tea (hot extraction) was reported previously by our group [55]. Recently, we also confirmed its availability in SE FAE (cold extraction). 
Hydroxycinnamic acids are the most abundant phenolic acids in fruits, vegetables, and coffee beans [63]. They present as esters of hydroxycarboxylic acids, such as quinic acid or as glycosylated derivatives. Among them are caffeic acid, ferulic acid, chlorogenic acid, isoferulic acid and coumaric acid. There are data showing that SE fruits contain highest concentration of neochlorogenic acid and chlorogenic acid among all Sambucus sp., followed by Sambucus cerulea [15]. The same authors report also presence of p-coumaric acid-Oglucoside, 3-O-p-coumaroylquinic acid, and 4-O-p-coumaroylquinic acid in SE fruits. A study on SE fruit tea confirmed the presence of these hydroxycinnamic acids and those that we have also found in SE FAE [55]. There was no significant difference in hydroxycinnamic acid content between SE fruit tea prepared by hot and cold FAE extraction. In accordance with others, we have also found that the neochlorogenic acid followed by chlorogenic and 3-O-p-coumaroylquinic acid were the main hydroxycinnamic acids in SE FAE. The beneficial effects of hydroxycinnamic acids as potential chemo-preventives are associated to their antioxidant activity [64]. Coumaric and ferulic acid and their amides significantly reduce LPS-stimulated NO synthesis, iNOS protein content and mRNA levels in RAW 264.7 macrophages, thus presuming a mechanisms of their anti-inflammatory activity [65]. Plant extracts rich in neochlorogenic acid possess various biological activities, including antioxidant and anti-inflammatory [66-68]. As SE FAE is rich in hydroxycinnamic acids and their derivatives, it could be suggested that hydroxycinnamic acids are the main bioactive components determining its antioxidant, and anti-inflammatory.

The most abundant flavonol glycoside in Sambucus sp. is quercetin-3-O-rutinoside (rutin) [15]. Other flavonol glycosides detected in SE include quercetin glycosides, followed by kaempferol glycosides, and isorhamnetin glycosides [12,15,55]. In our samples the total amount of flavonols was $195.35 \mu \mathrm{g} / \mathrm{mL}$, comprising only $3.35 \%$ of all analyzed polyphenols. In addition, the quercetin glycosides $(128.63 \mu \mathrm{g} / \mathrm{mL})$ dominate over kaempferol glycosides $(66.72 \mu \mathrm{g} / \mathrm{mL})$, representing $65.85 \%$ and $34.15 \%$ respectively of all identified flavonols in SE FAE. The presence of flavonols, quercetin and kaempferol in SE fruit extracts was widely reported in the literature [16]. Other studies provide data regarding the content of rutin $[9,16,55]$, isoquercetin and hyperoside $[9,15,55]$, kaempferol 3O-rutinoside [15], isorhamnetin-3-O-laminaribioside [12], isorhamnetin 3-O-rutinoside (narcissin) [12,15], isorhamnetin 3-O-glucoside [9,12], and myricetin [16] in SE fruit extracts. In accordance with the data of others, we have also identified quercetin-3-Orhamnosyl-galactoside, quercetin-3-O-rhamnosyl-glucoside, guaiaverin, quercetin-3-Oxyloside, kaempferol-3-O-galactoside, astragalin, kaempferol-3-O-rhamnosyl-galactoside, kaempferol-3-O-rhamnosyl-glucoside, kaempferol-3-O-arabinoside, kaempferol-3-Oxyloside in our samples [55]. Flavonoid-rich herb extracts possess strong antioxidant and anti-inflammatory activities $[69,70]$. Both isoquercetin and hyperoside exert antioxidant and anti-inflammatory [71,72] effect. Similarly, quercetin and rutin exhibit antiinflammatory, anti-cancer, anti-bacterial and anticonvulsant activities [73-75].

\subsection{SE FAE Modulates mRNA and Protein Levels of Inflammation-Related Biomarkers in LPS-Challenged J774A.1 Macrophages}

The anti-inflammatory effect of polyphenols is due to the decreased activation of macrophages and T-lymphocytes and the suppressed production of cytokines and chemokines or their receptors. Polyphenols such as resveratrol, catechin and quercetin, found in SE fruits, inhibit NFKB-dependent production of ICAM and VCAM in endothelial cells, as well as the expression of MCP-1 receptors CCR1 and CCR2 [76,77]. Inhibition of the latter reduces the chemotaxis of leukocytes to the site of inflammation and the subsequent increased production of IL-6. Anthocyanin metabolites reduce TNF $\alpha$-induced expression of MCP-1 and ICAM, and thus combat oxidative stress. In models of LPS-induced inflammatory response of macrophages, anthocyanidin- and anthocyanin-rich extracts inhibit iNOS transcription and iNOS and COX-2 translation by targeting the NFKB and MAPK kinase signaling pathways [78,79]. Karlsen et al. [80] reported that blackcurrant and blackberry polyphenols significantly inhibited NFKB in LPS challanged monocytes isolated from healthy adults. 
In our previous study we found that SE FAE reduces LPS activated mRNA expression of NFKB, which correlated with decreased transcription levels of glutamate-cysteine ligase and glutathione peroxidase enzymes [18]. Neochlorogenic and chlorogenic acid, also found in SE FAE, suppress LPS-stimulated activation of NFKB patway resulting in reduced iNOS synthesis and activation of COX-2, thus decreasing NO, prostaglandin E2, TNF $\alpha$, IL-1 $\beta$, and IL-6 levels in RAW 267 macrophages [81]. Neochlorogenic and chlorogenic acid-rich plant extracts significantly reduce the carrageenan-induced paw edema in rats, in vivo [81]. Coumaric and ferulic acids were found to reduce LPS-stimulated iNOS protein and mRNA levels [65]. Few studies have reported the strong antioxidant, anti-inflammatory and antidiabetic properties of cyanidin-3-O-galactoside, one of the main anthocyanin in SE FAE [54]. Ursolic acid, found in SE leaves, reveals anti-inflammatory activity by reducing $\mathrm{TNF} \alpha$-induced expression of ICAM- 1 and VCAM- 1 in human umbilical vein endothelial cells [82]. Ursolic acid reduces LPS-stimulated NFKB [44] and JNK signaling, thus inhibiting inflammatory cytokine production [45]. It was reported, also, that it may combat ER stressand NFKB-related inflammation in animals on a high-fat diet [46]. We also found an antiinflammatory effect of SE FAE, which may be due to the presence of ursolic acid in SE fruits reported by others [12].

LPS stimulates the gene expression of cytokines IL- $1 \beta$, TNF $\alpha$ and IL-6, chemokine ICAM- 1 and the enzymes COX-2 and iNOS by activating the NFKB-dependent signaling pathway [83-88]. The activation of iNOS results in increased production of $\mathrm{ONOO}^{-}$and further stimulation of COX2 gene expression and prostaglandin E2 production [89]. Recently we observed that the pre-treatment with SE FAE significantly reduces LPS-stimulated transcription of pro-inflammatory cytokines IL-1 $\beta, \mathrm{TNF} \alpha$, IL-6, the chemokines MCP-1, ICAM-1, enzymes COX-2, iNOS, as well as the protein levels of iNOS.

The effect was comparable to that of salicylic acid, a known anti-inflammatory agent, used in our study as a positive control. The possible mechanism behind the observed anti-inflammatory effect of SE extract might due to the presence of neochlorogenic acid, chlorogenicacid, ursolic acid, resveratrol, catechin and quercetin, by suppressing the NFkB signaling pathway. Additional mechanism for reducing COX2 activity and prostaglandin production might be the direct NO radical-scavenging activity of SE FAE [8].

Moreover, when applied alone, the lower doses of SE FAE induce the transcription of IL-6, TNF $\alpha$ and MCP- 1 by two-fold; COX2 and iNOS transcription by three-fold and iNOS protein expression $(p<0.05)$. These results support the traditional application of dwarf elderberries in folk medicine as an effective immunostimulant. Our previous study reported increased NFKB, glutamate-cysteine ligase and glutathione peroxidase transcription and thus confirms the immunostimulatory effect of SE FAE [18]. Immunostimulatory effect was also proven for S. nigra, another member of the genus Sambucus [90].

NADPH oxidase (NOX), is one of the major enzymes in vascular endothelial cells, catalyzing the formation of a superoxide radical anion [91]. Endothelial eNOS, as well as iNOS, produce NO, which reacts with a superoxide radical anion forming highly reactive $\mathrm{ONOO}^{-}[92,93]$ and contributing to the development of oxidative stress. NOX is highly active in activated macrophages, taking part in a respiratory burst for destroying bacterial cell walls [94]. NOX is among the newly established target molecules in the treatment of hypertension and atherosclerosis, and concomitant pathologies such as diabetes and cardiovascular diseases [91,95].

By suppressing the LPS-induced gene expression of NOX subunit Noxo1, SE FAE exhibits strong antioxidant and anti-inflammatory activity. The effect of the extract on LPS-induced Noxo1 transcription was similar to that of SA. Both SE FAE and SA are very effective in completely neutralizing LPS-induced Noxo1 overexpression. Compounds such as epigallocatechin gallate, quercetin and isorhamnetin, the derivatives of which are found in SE fruits, were shown to target Noxo1 [96-101], while resveratrol decreases NOX activity [102]. NOX, and in particular its Noxo1 subunit, has been suggested as playing an important role in the IL-1 $\beta$-dependent activation of NF- $\mathrm{kB}$ [103]. Therefore, the inhibition 
of Noxo1 gene expression is one potential mechanism by which SE fruits suppress the NFKB-dependent expression of pro-inflammatory genes and proteins such as iNOS.

FABP4 one of the fatty acid-binding proteins is expressed in both adipocytes and macrophages $[104,105]$. Macrophages are specific target cells for Fabp4 and its deficiency prevents atherosclerosis [100]. High FFA contribute to the development of atherosclerosis, are proinflammatory and activate TLR4 signaling cascades. The same signaling pathway is also activated by LPS [25]. In animal models of obesity and insulin resistance it was shown that the inhibition of FABP4 protein in macrophages reduces inflammatory cytokines (MCP-1, IL-1 $\beta$, IL-6 and TNF $\alpha$ ) and the formation of atherosclerotic lesions and foam cells and improves insulin sensitivity $[106,107]$. Recently, we studied the effect of SE FAE on the transcription levels of the Fabp4 gene. SE FAE, applied alone, slightly stimulated Fabp4, as was observed for other studied inflammatory genes. On the other hand, in LPS-stimulated cells, pre-treatment with the same concentrations of SE FAE completely prevents LPS-stimulated Fabp4 transcription. These findings suggest another possible anti-inflammatory mechanism of SE FAE action.

SIRT-1 is among the most studied sirtuins from class III histone deacetylases, which activation improves obesity related insulin resistance [108] and possesses anti-inflammatory potential [25]. Sirt-1 activators, such as resveratrol, may inhibit ICAM1 and TNF $\alpha$ induction [109]. In our study, SE FAE induces the expression of Sirt-1. The same result is observed in macrophages pre-treated with the extract and stimulated by LPS. SIRT-1 decreases serine phosphorylation in IRS-1, improves insulin signaling and, as a consequence, increases glucose transport [110]. The same mechanism is involved in improving insulin sensitivity decreased by TNF-alpha. These findings suggest another possible anti-inflammatory and insulin sensing mechanism of SE FAE, although these mechanisms are unclear and require additional studies in future.

\subsection{SE FAE Modulates Levels of ER Stress-Related Proteins in LPS-Challenged J774A.1 Macrophages}

Activation of ER stress may lead to the phosphorylation of JNK and IKK, which is wellknown to promote NFKB signaling and the consequent inflammation [32] accompanied by JNK-mediated phosphorylation of IRS $1 / 2$ [111] to impair insulin signaling. On the other hand, triggered by viral or bacterial infections, the production of TNF $\alpha$, IL-6, IL- $1 \beta$, and INF $\gamma$ may amplify the ER stress in many cell types including macrophages, pancreatic $\beta$ cells and hepatocytes $[112,113]$. Since both the processes of inflammation and ER stress may result from each other, we analyzed the expression of three important ER stress-related proteins as potential mechanisms to explain the observed anti-inflammatory potential of SE FAE.

We have observed a significant increase in protein levels of transcription factors ATF6 $\alpha$ and peIF $2 \alpha$ and their downstream target CHOP in LPS-stimulated macrophages. Applied alone SE FAE downregulated the synthesis of CHOP at a dose-dependent manner and slightly that of ATF6 $\alpha$. SE FAE significantly reduced LPS-stimulated CHOP levels. The decrease in ATF6 $\alpha$ levels and the phosphorylated eIF $2 \alpha$ in LPS-stimulated macrophages provides evidence for a possible mechanism by which the extract inhibits $\mathrm{CHOP}$ synthesis. This cytoprotective mechanism in the case of stimulated ER stress is confirmed by the established high significant correlation between protein levels of CHOP and transcription factors (Figure 5). This may explain the previously reported cytoprotective effects of SE fruits as well $[9,19]$. SA reduced only the LPS-stimulated peIF $2 \alpha$ protein levels. It should be noted that the SE FAE effect was in a similar direction, however it was stronger than that of SA. With regard to the well-known anti-inflammatory activities of SA [114] and the links between inflammation and the activation of ER stress, we expected that SA might have reducing effect on ER stress-related biomarkers. However, SA did not exhibit any protective effect against LPS-stimulated ATF6 $\alpha$ and CHOP levels, as SE FAE, in contrast, did. According to this observation, we may suggest that the SE FAE uses mechanisms different from those of SA, resulting not only in reduced transcription of inflammatory markers but also in the translation of ER stress-related ones. 
ER stress could be activated by high levels of FFAs, similarly to inflammation, excess nutrients, improperly folded proteins and local hypoxia, which is characteristic of obesity. This results in increased oxidative stress in the liver and in adipose tissue of obese animals [115]. An interesting fact is the established activated expression of Fabp4 in macrophages and its association with the development of ER stress and inflammation [106]. In accordance with previous analyses, the suppression of Fabp4 in macrophages protects cells from the FFA-induced inflammatory process, which may result in increased insulin sensitivity and glucose tolerance [106]. The ability of the SE FAE to inhibit LPS-induced transcription of Fabp4 suggests that it would also have a protective effect in combating ER stress. FFA and glucose activate PERK-mediated phosphorylation and activation of eIF2 $\alpha$ and RNA splicing of Xbp-1 in obese rat and human adipocytes $[116,117]$. CHOP is induced predominantly by the PERK/eIF2 $\alpha /$ ATF 4 signaling cascade associated with ER stress, as well as by the IRE $1 \alpha / \mathrm{Xbp}-1$ signaling pathway and the ATF6 $\alpha$ transcription factor in different pathological conditions, including diabetes [118-121].

The induction of CHOP is associated with the activation of apoptosis and DNA damage. Its induction in humans and animal macrophages is associated with the detachment of atherosclerotic plaques in atherosclerosis [122]. The production of superoxide by NOX in atherosclerotic plaque-associated macrophages activates $\mathrm{CHOP}$ and subsequent ER stress-mediated cell death [123]. ER stress may stimulate NFKB, by $\mathrm{Ca}^{2+}-$ and reactive oxygen species-dependent mechanisms [124] and the activation of PERK/eIF $2 \alpha$-mediated phosphorilation of IKK [125]. Another important mediator of the ER stress-related activation of NFKB signaling and the consequent TNF $\alpha$, IL- 6 and IL- $1 \beta$ cytokines production is iNOS [34]. This transforms iNOS enzyme into a cross point of inflammation and ER stress, and, consequently intoa possible therapeutic targets.

By preventing the LPS-induced transcription of iNOS and Noxo1 and the subsequent translation of iNOS protein, SE FAE may reduce superoxide radical and $\mathrm{ONOO}^{-}$production, thus reducing the activation of ER stress-related inflammation; whereas, suppressing $\mathrm{CHOP}$ synthesis by suppression of peIF2 and ATF6 $\alpha$ possess another important mechanism for combating ER stress-related activation of inflammation and cytokine production. These are the first results confirming that $\mathrm{SE}$, and in particular SE fruits, could suppress the induction of inflammation by suppressing the activation of ER stress.

The complex phytochemical composition of SE FAE presumes that it acts at different levels on inflammation and ER stress regulatory cascades. SE FAE acts at different crosspoints starting from the direct scavenging of reactive oxygen species, through the regulation of gene transcription, to protein synthesis.

Our results contribute to the relationship between inflammation, ER stress and insulin resistance. We may speculate that SE FAE could have a beneficial effect in preventing atherosclerosis, insulin resistance and diabetes type 2 , but this requires additional specific studies to confirm the possible insulin sensing effect of the SE fruits.

\section{Materials and Methods}

\subsection{Plant Material}

Well-ripened fruits of Sambucus ebulus L. were harvested from North-Eastern Bulgaria in the period August-September, 2014 and were dried in the dark at room temperature. SE FAE was prepared using $150 \mathrm{mg}$ finely grounded dry fruits, extracted three times with $3 \mathrm{~mL}$ distilled water for $3 \mathrm{~min}$ in a vortex mixer (2000 rpm), at room temperature. After centrifugation ( $5 \mathrm{~min}, 3500 \mathrm{rpm}$ ) the supernatants were collected and diluted up to $15 \mathrm{~mL}$ with PBS buffer $(\mathrm{pH}=7.4)$ for cell-culture experiments or with distilled water for phytochemical analyses. A specimen from S. ebulus L. fruits was deposited under No. 108144 in the Herbarium SO (by Index Herbariorum) of Sofia University St. Kliment Ohridski, Faculty of Biology. 


\subsection{Phytochemical Analysis}

\subsubsection{Extraction}

The samples were filtered through a $0.45-\mu \mathrm{m}$ PTFE filter (Waters, USA) and the filtrates were loaded onto a reverse phase solid phase extraction column (Discovery ${ }^{\circledR}$ DSC-18, $5 \mathrm{~g}$, $20 \mathrm{~mL}$ ) (Sigma-Aldrich Co. LLC, St. Louis, MO, USA). The SPE columns were activated rinsed with $40.0 \mathrm{~mL}$ distilled water and $1 \mathrm{~mL}$ of the filtered sample was loaded onto the SPE column. Three fractions were isolated: anthocyanin fraction (C) - eluted with $2 \times 12 \mathrm{~mL} 0.1 \%(v / v)$ formic acid in acetonitrile; non-anthocyanin fraction (B) containing phenolic acids, flavonols, flavonols, eluted with a $2 \times 12$-mL ethyl acetate; polar fraction (A), containing organic acids, aminoacids and carbohydrates-eluted with $2 \times 12-\mathrm{mL} 0.2 \%$ $(v / v)$ formic acid in water. The eluates were evaporated to dryness under reduced pressure at a temperature below $40{ }^{\circ} \mathrm{C}$.

\subsubsection{Analysis of Polar Fraction (A)}

An aliquot $(0.2 \mathrm{~mL})$ of fraction A was submitted to lyophilisation for $6 \mathrm{~h}$ at $-20^{\circ} \mathrm{C}$. The dry residue was subjected to the following derivatization protocol: $300.0 \mu \mathrm{L}$ solution of methoxyamine hydrochloride $(20.0 \mathrm{mg} / \mathrm{mL}$ in pyridine) was added to a residue and the mixture was heated on Thermo-Shaker TS-100 $\left(1 \mathrm{~h} / 70{ }^{\circ} \mathrm{C} / 300 \mathrm{rpm}\right)$. After cooling, $100.0 \mu \mathrm{L} \mathrm{N}, \mathrm{O}-\mathrm{Bis}$ (trimethylsilyl)trifluoroacetamide (BSTFA) were added to the mixture, then heated on Thermoshaker, Analytik Jena AG, Jena, Germany $\left(40 \mathrm{~min} / 70^{\circ} \mathrm{C} / 300 \mathrm{rpm}\right)$. Then, $1.0 \mu \mathrm{L}$ of the solution was injected in the GC-MS system (Agilent GC 7890, Agilent MD 5975). The separations were done on a chromatographic column HP-5ms (length $30 \mathrm{~m}$, diameter $0.32 \mathrm{~mm}$, film thickness $0.25 \mu \mathrm{m}$ ) at a gradient temperature mode: initial $100{ }^{\circ} \mathrm{C}$ for $2 \mathrm{~min}$; ramp up to $180^{\circ} \mathrm{C}$ with $15^{\circ} \mathrm{C} / \mathrm{min}$ for $1 \mathrm{~min}$; ramp up to $300^{\circ} \mathrm{C}$ with $5^{\circ} \mathrm{C} / \mathrm{min}$ for $10 \mathrm{~min}$. Injector and detector temperatures were set at $250^{\circ} \mathrm{C}$; the velocity of the carrier gas helium was set at $1.0 \mathrm{~mL} / \mathrm{min}$. The MS scanning was in the range $50-550 \mathrm{~m} / \mathrm{z}$.

\subsubsection{Analysis of Fractions B and C}

Fractions $B$ and $C$ were analyzed using LC-PDA-ESI-MS/MS chromatographic system; in negative ESI mode for fraction $\mathrm{B}$, and in positive ESI mode for fraction $\mathrm{C}$ as previously described [55].

For the analysis of polyphenolics, the dry residues of fraction $B$ and $C$ were dissolved in $200 \mu \mathrm{L}$ metahnol:formic acid, $(99: 1 v / v)$, the solution was filtered through a $0.22 \mu \mathrm{m}$ PTFE filter and $2 \mu \mathrm{L}$ of the filtrate were injected into LC-PDA-ESI-MS/MS system.

An LTQ Orbitrap mass spectrometer (Thermo Scientific, Hemel Hempstead, UK) equipped with an ESI source (in negative mode) was used for accurate mass measurements. Operation parameters were as follows: source voltage $-4 \mathrm{kV}$; sheath, auxiliary and sweep gas $-20,10$ and 2 arbitrary units, respectively; capillary temperature was $275^{\circ} \mathrm{C}$. The samples were analyzed in full-scan mode at a resolution of 30,000 at $\mathrm{m} / \mathrm{z} 400$ and datadependent MS/MS events were acquired at a resolving power of 15,000. The most intense ions were detected during full-scan MS-activated data-dependent scanning. Ions that were insufficiently intense were analyzed in MS2 mode with a resolution power of 15,000 at $\mathrm{m} / \mathrm{z}$ 400. An isolation width of $100 \mathrm{amu}$ was used. Precursors were fragmented by a collision-induced dissociation with energy of $30 \mathrm{~V}$ and an activation time of $10 \mathrm{~ms}$. The mass range in FTMS mode was from m/z 100 to 1000. The data analyses were performed using XCalibur software v2.0.7 (Thermo Fisher Scientific, Hemel Hempstead, UK).

Chromatographic separations were performed on an Accela chromatograph (Thermo Scientific, Waltham, MA, USA) equipped with a quaternary pump, a photodiode array detector (PDA) and a thermostated autosampler. A Kinetex C18 column $(100 \AA, 2.6 \mu \mathrm{m}$, $150 \times 2.1 \mathrm{~mm}$ ) was used to perform chromatographic separations (Phenomenex Inc., Torrance, CA, USA). The elution was done in a gradient mode with water $/ 0.1 \%$ formic acid (solvent A) and acetonitrile (solvent $\mathrm{B}$ ) at a constant flow rate of $0.3 \mathrm{ml} / \mathrm{min}$. The gradient composition of the mobile phase was as follows: $0 \mathrm{~min}, 10 \% \mathrm{~B} ; 1 \mathrm{~min}, 10 \% \mathrm{~B} ; 15 \mathrm{~min}, 30 \%$ 
B; $22 \mathrm{~min}, 50 \%$ B; $28 \mathrm{~min}, 100 \%$ B; $34 \mathrm{~min}, 100 \% \mathrm{~B}, 36 \mathrm{~min}, 10 \%$ B. prior each analysis the column was equilibrated for $6 \mathrm{~min}$. The total run time was $36 \mathrm{~min}$.

\subsubsection{Identification and Quantitative Analysis}

The identification of compounds in fraction A was done either by comparison the retention times and Kovats indexes (RI) of the tested compounds with the same parameters of the corresponding pure standards or with mass spectra from the Golm Metabolome Database (http:/ / csbdb.mpimp-golm.mpg.de/csbdb/gmd/gmd.html, 30 August 2021) and NIST'08 (National Institute of Standards and Technology, Gaithersburg, MD, USA) libraries.

The quantification of phenolics in fractions $B$ and $C$ was performed by the external standard method as previously described [55]. Fifteen phenolic compounds were confirmed by comparing their retention times, exact masses and fragmentation patterns with corresponding standards. The identification of the remaining compounds without available standards was based on accurate mass measurements of the $[\mathrm{M}-\mathrm{H}]^{-}$ions and the fragmentation patterns, which was compared with the literature data.

\subsection{Cell Culture}

J774A.1 mouse macrophages were purchased from American Type Culture Collection (ATCC, Manassas, VA, USA). Cells were cultured in $75 \mathrm{~cm}^{3}$ flasks at $37{ }^{\circ} \mathrm{C}$ in a humidified chamber (CO2CELL48, MMM Medcenter Einrichtungen GmbH, Planegg, Germany) with 95\% air and 5\% CO2 in Dulbecco's Modified Eagle Medium (DMEM, with $4.5 \mathrm{~g} / \mathrm{L}$ of glucose and L-glutamine) (LONZA, Verviers, Belgium) supplemented with 10\% heat-inactivated fetal bovine serum (FBS, Sigma-Aldrich, Taufkirchen, Germany) and 1\% antibiotics (100 U/mL penicillin, $100 \mu \mathrm{g} / \mathrm{mL}$ streptomycin) (LONZA, Verviers, Belgium). Cells were sub-cultivated until they reach $80 \%$ confluence. Cell counts were prepared in quadruplicate by $0.4 \%$ trypan blue exclusion dye (Chemapol, Prague, Czech Republic) using a counting Burker chamber.

\subsection{Study Design}

The experimental model involved macrophage cells seeded in 6-well plates $\left(2 \times 10^{5}\right.$ cells/well $)$ and allowed to adhere overnight. The study design included the following experimental groups: (1) cells treated only with LPS; (2) cells treated with SE FAE; (3) cells pre-treated with SE FAE and consequently challenged with LPS. For control groups, we used untreated cells (blank); salicylic acid-treated cells (positive, antiinflammatory control) and cells pre-treated with salicylic acid and consequently challenged with LPS.

Cells were pre-treated with SE FAE with increasing concentrations of $2.5 \%, 5 \%$ and $10 \% v / v(0.25 \mathrm{mg} \mathrm{DW} / \mathrm{mL}, 0.5 \mathrm{mg} \mathrm{DW} / \mathrm{mL}, 1 \mathrm{mg} \mathrm{DW} / \mathrm{mL}$, respectively) or salicylic acid $(100 \mu \mathrm{M})$ (Merck, Germany) dissolved in DMEM (with $4.5 \mathrm{~g} / \mathrm{L}$ glucose, w /o phenol red and L-glutamine) supplemented with 10\% heat-inactivated FBS, $100 \mathrm{U} / \mathrm{mL}$ penicillin/100 $\mu \mathrm{g} / \mathrm{mL}$ streptomycin mixture and $2 \mathrm{mM}$ L-glutamine. After $24 \mathrm{~h}$ cells were treated with $200 \mathrm{ng} / \mathrm{mL}$ LPS (Escherichia coli 026:B6, Sigma-Aldrich, Taufkirchen, Germany) or not, by the simple refreshing of culture media and incubated for additional $24 \mathrm{~h}$. Following the last incubation period, the cells were lysed and total RNA or total protein were extracted and subjected to subsequent analyses. All treatments were performed in triplicate.

\subsection{Gene Expression Analysis}

\subsubsection{RNA Extraction and cDNA Synthesis}

Total RNA was extracted using TRI reagent (Ambion, Waltham, MA, USA) according to the manufacturers' requirement. RevertAid First Strand cDNA Synthesis kit (ThermoFisher Scientific, Waltham, MA, USA) was used to reversely transcribe $20 \mathrm{ng}$ of total RNA using oligo $(\mathrm{dT})_{18}$ priming strategy. Following the manufacturers' protocol reaction 
conditions in final volumes of $10 \mu \mathrm{L}$ were provided. cDNA synthesis was performed on GeneAmp PCR 7500 thermal cycler (Applied Biosystems, Waltham, MA, USA). After synthesis cDNA was diluted by adding of $30 \mu \mathrm{L}$ nuclease-free distilled water to each sample and stored at $-80^{\circ} \mathrm{C}$.

\subsection{2. qPCR Analysis}

Gene transcription levels were analyzed using the qPCR method and performed on an ABI PRISM 7500 (Applied Biosystems, Waltham, MA, USA). KAPA SYBR ${ }^{\circledR \circledast}{ }^{\circledR}$ FAST qPCR Master Mix (2X) with low ROX (KAPA Biosystems, Cape Town, South Africa) was used. The amplification reaction's final volume was $5 \mu \mathrm{L}$ in 96 -well plates, with $0.39 \mu \mathrm{L}$ of cDNA template. Final concentration of primers' was $300 \mathrm{nM}$. Reaction conditions were as follows: $95^{\circ} \mathrm{C} / 5 \mathrm{~min} ; 40$ cycles at $95^{\circ} \mathrm{C} / 15 \mathrm{sec}$ and $60^{\circ} \mathrm{C} / 1 \mathrm{~min}$. A dissociation step was added to the instrument's protocol to check for nonspecific amplification. As an internal control, the $\beta$-actin gene was used. Relative gene expression levels were calculated using the $2^{-\Delta \Delta \mathrm{Ct}}$ method [126]. The used primer sequences (Sigma-Aldrich, Taufkirchen, Germany) for each gene analyzed are presented in Table 3. Expression levels of mRNA are presented as relative units (RU) compared to the untreated control group of cells, where the levels of mRNA expression were considered to be equal to 1 . Analyses were performed in triplicate and included all cell groups in one plate while testing the expression of each gene.

Table 3. Oligonucleotide sequences of all used qPCR primer sets.

\begin{tabular}{|c|c|c|}
\hline Gene Name & Forward Primer $\left(5^{\prime}-3^{\prime}\right)$ & Reverse Primer $\left(5^{\prime}-3^{\prime}\right)$ \\
\hline$A c t b(\beta-a c t i n)$ & ACGGCCAGGTCATCACTATTG & CAAGAAGGAAGGCTGGAAAAG \\
\hline Ptgs2 (COX2) & TGAGCAACTATTCCAAACCAGC & GCACGTAGTCTTCGATCACTATC \\
\hline iNOS & GGCAGCCTGTGAGACCTTTG & GCATTGGAAGTGAAGCGTTTC \\
\hline$T N F \alpha$ & СССТСАСАСТСАGАТСАТСТTСТ & GCTACGACGTGGGCTACAG \\
\hline$I L-6$ & GAGTTGTGCAATGGCAATTCTG & GCAAGTGCATCATCGTTGTTCAT \\
\hline$I L-1 \beta$ & TTCAGGCAGGCAGTATCACTC & CCACGGGAAAGACACAGGTAG \\
\hline $\operatorname{Ccl} 2(\mathrm{MCP}-1)$ & AGGTGTCCCAAAGAAGCTGTA & ATGTCTGGACCCATTCCTTCT \\
\hline Sirt-1 & TGATTGGCACCGATCCTCG & CCACAGCGTCATATCATCCAG \\
\hline$I L-1 r a$ & GCTCATTGCTGGGTACTTACAA & CCAGACTTGGCACAAGACAGG \\
\hline Icam1 & GACCCCAAGGAGATCACATTC & GAAGATCGAAAGTCCGGA \\
\hline Noxo1 & AGAGGAGCCCTTATCCCAACC & TGTCCAGAATTTCTTGAGCCTTG \\
\hline Fabp4 (aP2) & AGTGAAAACTTCGATGATTACATGAA & GCCTGCCACTTTCCTTGTG \\
\hline
\end{tabular}

\subsection{Protein Expression Analysis}

\subsubsection{Protein Extraction and Quantification}

Total protein was extracted using Pierce ${ }^{\mathrm{TM}} \mathrm{IP}$ Lysis Buffer $(25 \mathrm{mM}$ Tris- $\mathrm{HCl} \mathrm{pH}$ 7.4, $150 \mathrm{mM} \mathrm{NaCl}, 1 \mathrm{mM}$ EDTA, 1\% NP-40 and 5\% glycerol) (Thermo Fisher Scientific, Waltham, MA, USA) with freshly added Halt ${ }^{\mathrm{TM}}$ Protease and Phosphatase Inhibitor Cocktail (Thermo Fisher Scientific, Waltham, MA, USA), according to the manufacturers' requirement. Prior to our analyses, total protein concentration was measured using a Bradford reagent (Protein assay dye concentrate, Bio-Rad Laboratories; Hercules, CA, USA) and calculated against a standard curve of standard bovine serum albumin (BSA) (Thermo Fisher Scientific, Waltham, MA, USA) dilutions.

\subsubsection{Western Blotting}

Protein lysates were subjected to SDS-PAGE, electrotransferred to a polyvinylidene difluoride membranes (PVDF; Merck Millipore; Billerica, MA, USA) and subsequently incubated with the following antibodies: ATF6 $\alpha$ (90 kDa) (1:1000, sc-166659), CHOP (GADD153) (26 kDa) (1:1000, sc-7351), peIF2 $\alpha$ (Ser52) (36 kDa) (1:1000, sc-12412), iNOS (1300 kDa) (1:1000, sc-7271) (Santa Cruz Biotechnology; Santa Cruz, CA, USA) and $\beta$-actin (42 kDa) (1:5000; A5316) (Sigma; St. Louis, MO, USA) after incubating the membranes with $3 \%$ BSA ( $\beta$-actin, ATF6 $\alpha$ ), $5 \%$ BSA (peIF2 $\alpha$ ) or $5 \%$ skim milk (CHOP, iNOS) blocking buffer. Specific antigen-antibody bindings were detected using horseradish-peroxidase conjugated secondary antibodies (Dako Denmark; Glostrup, Denmark) and an enhanced 
chemiluminescence detection method, according to the manufacturer's instructions (Pierce ECL Western Blotting Substrate; Thermo Scientific, Waltham, MA, USA) as described previously $[127,128]$. Autoradiographic films (Fujifilm; Tokyo, Japan) were scanned and the band's signal was quantified by densitometry using ImageJ-1.53 software (National Institutes of Health, Bethesda, MD, USA). Values were expressed relative to $\beta$-actin.

\subsection{Statistical Analysis}

GraphPad Prism v7.0 software (GraphPad Software, Inc.; La Jolla, CA, USA) was used to perform the statistical analyses (Student's $t$-tests, Spearman correlation, 95\% CI). The values of $p<0.05$ were considered as significant. Data were presented as mean $\pm \mathrm{SD}$ (concentration of phytochemical) or \pm SEM (mRNA and protein expression levels). All analyses and treatments were performed in triplicates.

\section{Conclusions}

The SE FAE is confirmed to be rich in phytochemicals, predominantly hydroxycinnamic acids, anthocyanins, proanthocyanidins and resveratrol, with strong antioxidant-, anti-inflammatory- and ER stress-reducing potential, as well as in AAs including essential ones, organic acids, alcohols and saturated and unsaturated fatty acids and esters, some of them reported for first time in SE fruits.

Considering the results, we may conclude that SE FAE, applied alone, possesses immunostimulating potential, without promoting any additional stress, such as ER stress. It may reduce the ER stress-related expression of the CHOP protein, independently from its immunostimulating potential. The SE fruit extract exerted significant antioxidant and anti-inflammatory action, decreasing the LPS-stimulated transcription of oxidative stress, inflammation, atherosclerosis and insulin resistance-related cytokines, chemokines and enzymes, as well as the translation of iNOS. The herb extract possesses significant ER stressreducing potential, by suppressing the LPS-stimulated synthesis of peIF2 $\alpha$, ATF6 $\alpha$ and $\mathrm{CHOP}$ proteins. Taken together, these results reveal a new possible mechanism explaining the anti-inflammatory potential of SE fruits, by targeting ER stress and related biomarkers.

These findings are in concordance with the traditional usage of SE fruits and its FAE as potential natural immunomodulation preparation, beneficial in the prevention or treatment of oxidative stress- and inflammation-related conditions.

Supplementary Materials: The following are available online at https:/ / www.mdpi.com/article/10 .3390 / plants10112446/s1, Figure S1: Representative chromatogram of analyzed polar compounds (fraction A) by GC-MS technique, Figure S2: Representative LC-PDA-ESI-MS/MS chromatogram of Sambucus ebulus L. fruit anthocyanins (1-Cyanidin-3-O-Galactoside, 2-Cyanidin-3-O-Glucoside, 3-Cyanidin-3-O-Arabinoside, 4-Cyanidin-3-O-Xyloside), Figure S3: Representative LC-PDA-ESIMS/MS chromatogram of Sambucus ebulus L. fruit proanthocyanidin monomers, Figure S4: Representative LC-PDA-ESI-MS/MS chromatogram of Sambucus ebulus L. fruit proanthocyanidin di-and trimers, Figure S5: Representative LC-PDA-ESI-MS/MS chromatogram of Sambucus ebulus L. fruit stilbenes, Figure S6: Representative LC-PDA-ESI-MS/MS chromatogram of Sambucus ebulus L. fruit hydroxycinnamic acids (1-3-O-Caffeoylquinic acid, 2-Caffeic acid-O-galactoside, 3-Caffeic acid-O-glucoside, 4-5-O-Caffeoylquinic acid, 5-p-Coumaric acid-O-glucoside, 6-3-O-pCoumaroylquinic acid, 7-Feruloylquinic acid; 8-4 -O-p-Coumaroylquinic acid; 9-Ferulic acid-Ogalactoside; 10-Ferulic acid-O-glucoside), Figure S7: Representative LC-PDA-ESI-MS/MS chromatogram of Sambucus ebulus L. fruit flavonols (1-Kaempferol-3-O-arabinoside, 2-Kaempferol-3O-xyloside), Figure S8: Representative LC-PDA-ESI-MS/MS chromatogram of Sambucus ebulus L. fruit flavonols (1-Quercetin-3-O-galactoside, 2-Quercetin-3-O-glucoside), Figure S9: Representative LC-PDA-ESI-MS/MS chromatogram of Sambucus ebulus L. fruit flavonols (1-Kaempferol-3-Orhamnosyl-galactoside, 2-Kaempferol-3-O-rhamnosyl-glucoside), Figure S10: Representative LCPDA-ESI-MS/MS chromatogram of Sambucus ebulus L. fruit flavonols (1-Quercetin-3-O-rhamnosylgalactoside, 2-Quercetin-3-O-rhamnosyl-glucoside), Figure S11: Representative LC-PDA-ESI-MS/MS chromatogram of Sambucus ebulus L. fruit flavonols (1-Kaempferol-3-O-galactoside, 2-Kaempferol-3O-glucoside), Figure S12: Original Western blot gels presenting the changes in protein levels of iNOS, 
peIF2 $\alpha$, ATF6 $\alpha$ and CHOP in J774A.1 mouse macrophages pre-treated with increasing concentrations $(2.5 \%, 5 \%, 10 \% v / v)$ of SE FAE or with SA for $24 \mathrm{~h}$ and subsequently stimulated or not with LPS, Table S1: Relative Kovat's retention index (RI) of analyzed polar compounds (fraction A) presented in Table 1, using GC-MS technique, Table S2: Precursor ion and fragment ion mass-to-charge ratios $(\mathrm{m} / \mathrm{z})$ of the analyzed polyphenols using the LC-PDA-ESI-MS/MS technique.

Author Contributions: Writing — original draft, methodology, formal analysis, investigation, conceptualization, project administration and funding acquisition O.T.; writing-methodology, resources and formal analysis, I.D. and I.B.; writing—review and editing Y.K.-K.; writing—review and editing, resources, supervision R.N.; writing-review and editing, resources, supervision, conceptualization B.G. and D.I. All authors have read and agreed to the published version of the manuscript.

Funding: This research was funded by Ministry of Education and Science of Bulgaria, grant number 94-14863/01.07.2013, project "Science and business", BG051PO001-3.3-05/0001. The APC was funded by Medical University-Varna, Bulgaria.

Institutional Review Board Statement: Not applicable.

Informed Consent Statement: Not applicable.

Data Availability Statement: The data presented in this study are available in the article.

Acknowledgments: This study was supported by Medical University-Varna, Bulgaria. We would like to acknowledge the support of Carlos Dieguez, and Ruben Nogueiras laboratory team members from CIMUS, for the hospitality and support while maintaining the western blot analyzes.

Conflicts of Interest: The authors declare no conflict of interest.

\section{References}

1. Kültür, Ş. Medicinal plants used in Kırklareli Province (Turkey). J. Ethnopharmacol. 2007, 111, 341-364. [CrossRef] [PubMed]

2. Tasinov, O.; Kiselova-Kaneva, Y.; Ivanova, D. Sambucus ebulus from traditional medicine to recent studies. Scr. Sci. Med. 2013, 45, 36-43. [CrossRef]

3. Ebrahimzadeh, M.A.; Pourmorad, F.; Bekhradnia, A.R. Iron chelating activity, phenol and flavonoid content of some medicinal plants from Iran. Afr. J. Biotechnol. 2008, 7, 3188-3192. [CrossRef]

4. Šarić-Kundalić, B.; Dobeš, C.; Klatte-Asselmeyer, V.; Saukel, J. Ethnobotanical study on medicinal use of wild and cultivated plants in middle, south and west Bosnia and Herzegovina. J. Ethnopharmacol. 2010, 131. [CrossRef] [PubMed]

5. Chirigiu, L.; Chirigiu, R.G.; Tircomnicu, V.; Bubulica, M.V. GC-MS analysis of chemical composition of Sambucus ebulus leaves. Chem. Nat. Compd. 2011, 47, 126-127. [CrossRef]

6. Marc, E.B.; Nelly, A.; Annick, D.D.; Frederic, D. Plants used as remedies antirheumatic and antineuralgic in the traditional medicine of Lebanon. J. Ethnopharmacol. 2008, 120, 315-334. [CrossRef]

7. Tasinov, O.; Kiselova-Kaneva, Y.; Ivanova, D. Antioxidant activity, total polyphenol content and anthocyanins content of Sambucus ebulus L. aqueous and aqueous-ethanolic extracts depend on the type and concentration of extragent. Sci. Technol. 2012, II, 37-41.

8. Ebrahimzadeh, M.A.; Nabavi, S.F.; Nabavi, S.M.; Pourmorad, F. Nitric oxide radical scavenging potential of some Elburz medicinal plants. Afr. J. Biotechnol. 2010, 9, 5212-5217. [CrossRef]

9. Tasinov, O.B.; Kiselova-Kaneva, Y.D.; Nazifova-Tasinova, N.F.; Todorova, M.N.; Trendafilova, A.B.; Ivanova, D.G. Chemical composition and cytoprotective and anti-inflammatory potential of Sambucus ebulus fruit ethyl acetate fraction. Bulg. Chem. Commun. 2020, 52, 100-106.

10. Pribela, A.; Durcanska, J.; Piry, J.; Karovicova, J. Volatile substances of dwarf elder (Sambucus ebulus) fruits. Biol. Ser. C 1992, 47, 225-230.

11. Bubulica, M.V.; Chirigiu, L.; Popescu, M.; Simionescu, A.; Anoaica, G.; Popescu, A. Analysis of sterol compounds from Sambucus ebulus. Chem. Nat. Compd. 2012, 48, 520-521. [CrossRef]

12. Zahmanov, G.; Alipieva, K.; Denev, P.; Todorov, D.; Hinkov, A.; Shishkov, S.; Simova, S.; Georgiev, M.I. Flavonoid glycosides profiling in dwarf elder fruits (Sambucus ebulus L.) and evaluation of their antioxidant and anti-herpes simplex activities. Ind. Crops Prod. 2015, 63, 58-64. [CrossRef]

13. Zahmanov, G.; Alipieva, K.; Simova, S.; Georgiev, M.I. Metabolic differentiations of dwarf elder by NMR-based metabolomics. Phytochem. Lett. 2015, 11, 404-409. [CrossRef]

14. Mikulic-Petkovsek, M.; Schmitzer, V.; Slatnar, A.; Todorovic, B.; Veberic, R.; Stampar, F.; Ivancic, A. Investigation of anthocyanin profile of four elderberry species and interspecific hybrids. J. Agric. Food Chem. 2014, 62, 5573-5580. [CrossRef]

15. Mikulic-Petkovsek, M.; Ivancic, A.; Todorovic, B.; Veberic, R.; Stampar, F. Fruit Phenolic Composition of Different Elderberry Species and Hybrids. J. Food Sci. 2015, 80, C2180-C2190. [CrossRef] 
16. Vankova, D.V.; Todorova, M.N.; Kisselova-Kaneva, Y.D.; Galunska, B.T. Development of new and robust LC-MS method for simultaneous quantification of polyphenols from Sambucus ebulus fruits. J. Liq. Chromatogr. Relat. Technol. 2019, 42, $408-416$. [CrossRef]

17. Tasinov, O.; Kiselova-Kaneva, Y.; Ivanova, D. Sambucus ebulus L. fruit aqueous infusion modulates GCL and GPX4 gene expression. Bulg. J. Agric. Sci. 2013, 19, 143-146.

18. Tasinov, O.B.; Kiselova-Kaneva, Y.D.; Ivanova, D.G. Effects of dwarf elder fruit infusion on nuclear factor kappa B and glutathione metabolism-related genes transcription in a model of lipopolysaccharides challenged macrophages. Bulg. Chem. Commun. 2020, $52,68-74$.

19. Todorova, M.; Tasinov, O.; Pasheva, M.; Vankova, D.; Ivanova, D.; Galunska, B.; Kiselova-Kaneva, Y. Cytoprotective activity of Sambucus ebulus fruit extracts in conditions of oxidative tert-buthyl-hydroperoxyde induced cell toxicity. Bulg. Chem. Commun. 2019, 51, 125-130.

20. Ebrahimzadeh, M.A.; Mahmoudi, M.; Karami, M.; Saeedi, S.; Ahmadi, A.H.; Salimi, E. Separation of active and toxic portions in Sambucus ebulus. Pak. J. Biol. Sci. 2007, 10, 4171-4173. [CrossRef]

21. Fathi, H.; Ebrahimzadeh, M.A.; Ziar, A.; Mohammadi, H. Oxidative damage induced by retching; antiemetic and neuroprotective role of Sambucus ebulus L. Cell Biol. Toxicol. 2015, 31, 231-239. [CrossRef] [PubMed]

22. Ivanova, D.; Tasinov, O.; Kiselova-Kaneva, Y. Improved lipid profile and increased serum antioxidant capacity in healthy volunteers after Sambucus ebulus L. fruit infusion consumption. Int. J. Food Sci. Nutr. 2014, 65, 740-744. [CrossRef]

23. Ivanova, D.; Nashar, M.; Kiselova-Kaneva, Y.; Tasinov, O.; Vankova, D.; Nazifova-Tasinova, N. The impact of human intervention studies on the evaluation of medicinal plant antioxidant and anti-inflammatory activities. In Human Health and Nutrition: New Research; Nova Science Publishers, Inc.: Hauppauge, NY, USA, 2015; pp. 145-166, ISBN 9781634828536.

24. Ebrahimzadeh, M.A.; Rafati, M.R.; Damchi, M.; Golpur, M.; Fathiazad, F. Treatment of paederus dermatitis with Sambucus ebulus lotion. Iran. J. Pharm. Res. 2014, 13, 1065-1072. [CrossRef] [PubMed]

25. Olefsky, J.M.; Glass, C.K. Macrophages, Inflammation, and Insulin Resistance. Annu. Rev. Physiol. 2010, 72, 219-246. [CrossRef] [PubMed]

26. Hotamisligil, G.S.; Arner, P.; Caro, J.F.; Atkinson, R.L.; Spiegelman, B.M. Increased adipose tissue expression of tumor necrosis factor-alpha in human obesity and insulin resistance. J. Clin. Investig. 1995, 95, 2409-2415. [CrossRef]

27. Hirosumi, J.; Tuncman, G.; Chang, L.; Görgün, C.Z.; Uysal, K.T.; Maeda, K.; Karin, M.; Hotamisligil, G.S. A central, role for JNK in obesity and insulin resistance. Nature 2002, 420,333-336. [CrossRef]

28. Bandyopadhyay, G.K.; Yu, J.G.; Ofrecio, J.; Olefsky, J.M. Increased p85/55/50 expression and decreased phosphotidylinositol 3-kinase activity in insulin-resistant human skeletal muscle. Diabetes 2005, 54, 2351-2359. [CrossRef]

29. Nguyen, M.T.A.; Favelyukis, S.; Nguyen, A.K.; Reichart, D.; Scott, P.A.; Jenn, A.; Liu-Bryan, R.; Glass, C.K.; Neels, J.G.; Olefsky, J.M. A subpopulation of macrophages infiltrates hypertrophic adipose tissue and is activated by free fatty acids via toll-like receptors 2 and 4 and JNK-dependent pathways. J. Biol. Chem. 2007, 282, 35279-35292. [CrossRef]

30. Boden, G. Insulin Resistance and Inflammation: Links between Obesity and Cardiovascular Disease. In Glucose Intake and Utilization in Pre-Diabetes and Diabetes: Implications for Cardiovascular Disease; Academic Press: Amsterdam, The Netherlands, 2015; pp. 95-101, ISBN 9780128005798.

31. Özcan, U.; Cao, Q.; Yilmaz, E.; Lee, A.H.; Iwakoshi, N.N.; Özdelen, E.; Tuncman, G.; Görgün, C.; Glimcher, L.H.; Hotamisligil, G.S. Endoplasmic reticulum stress links obesity, insulin action, and type 2 diabetes. Science 2004, 306, 457-461. [CrossRef]

32. Zhang, K.; Kaufman, R.J. From endoplasmic-reticulum stress to the inflammatory response. Nature 2008, 454, 455-462. [CrossRef]

33. Anthony, T.G.; Wek, R.C. TXNIP switches tracks toward a terminal UPR. Cell Metab. 2012, 16, 135-137. [CrossRef] [PubMed]

34. Jiang, M.; Wang, H.; Liu, Z.; Lin, L.; Wang, L.; Xie, M.; Li, D.; Zhang, J.; Zhang, R. Endoplasmic reticulum stress-dependent activation of iNOS/NO-NF- $\mathrm{BB}$ signaling and NLRP3 inflammasome contributes to endothelial inflammation and apoptosis associated with microgravity. FASEB J. 2020, 34, 10835-10849. [CrossRef]

35. Sun, Z.M.; Guan, P.; Luo, L.F.; Qin, L.Y.; Wang, N.; Zhao, Y.S.; Ji, E.S. Resveratrol protects against CIH-induced myocardial injury by targeting Nrf2 and blocking NLRP3 inflammasome activation. Life Sci. 2020, 245, 117362. [CrossRef]

36. Li, Y.; Xu, S.; Giles, A.; Nakamura, K.; Lee, J.W.; Hou, X.; Donmez, G.; Li, J.; Luo, Z.; Walsh, K.; et al. Hepatic overexpression of SIRT1 in mice attenuates endoplasmic reticulum stress and insulin resistance in the liver. FASEB J. 2011, 25, 1664-1679. [CrossRef]

37. Karthikeyan, B.; Harini, L.; Krishnakumar, V.; Kannan, V.R.; Sundar, K.; Kathiresan, T. Insights on the involvement of (-)-epigallocatechin gallate in ER stress-mediated apoptosis in age-related macular degeneration. Apoptosis 2017, $22,72-85$. [CrossRef]

38. Fu, K.; Chen, L.; Miao, L.; Guo, Y.; Zhang, W.; Bai, Y. Grape Seed Proanthocyanidins Protect N2a Cells against Ischemic Injury via Endoplasmic Reticulum Stress and Mitochondrial-associated Pathways. CNS Neurol. Disord.—Drug Targets 2019, 18, 334-341. [CrossRef] [PubMed]

39. NCI Thesaurus. Available online: https://ncit.nci.nih.gov/ncitbrowser/ConceptReport.jsp?dictionary=NCI_Thesaurus\&ns= NCI_Thesaurus\&code $=$ C82933 (accessed on 14 August 2021).

40. Veberic, R.; Jakopic, J.; Stampar, F.; Schmitzer, V. European elderberry (Sambucus nigra L.) rich in sugars, organic acids, anthocyanins and selected polyphenols. Food Chem. 2009, 114, 511-515. [CrossRef]

41. Washüttl, J.; Riederer, P.; Bancher, E. A qualitative and quantitative study of sugar-alcohols in several foods. J. Food Sci. 1973, 38, 1262-1263. [CrossRef] 
42. Chakravarti, B.; Maurya, R.; Siddiqui, J.A.; Kumar Bid, H.; Rajendran, S.M.; Yadav, P.P.; Konwar, R. In vitro anti-breast cancer activity of ethanolic extract of Wrightia tomentosa: Role of pro-apoptotic effects of oleanolic acid and urosolic acid. J. Ethnopharmacol. 2012, 142, 72-79. [CrossRef]

43. Juan, M.E.; Planas, J.M.; Ruiz-Gutierrez, V.; Daniel, H.; Wenzel, U. Antiproliferative and apoptosis-inducing effects of maslinic and oleanolic acids, two pentacyclic triterpenes from olives, on HT-29 colon cancer cells. Br. J. Nutr. 2008, 100, 36-43. [CrossRef]

44. Wang, Y.-J.; Lu, J.; Wu, D.-M.; Zheng, Z.H.; Zheng, Y.-L.; Wang, X.-H.; Ruan, J.; Sun, X.; Shan, Q.; Zhang, Z.-F. Ursolic acid attenuates lipopolysaccharide-induced cognitive deficits in mouse brain through suppressing $\mathrm{p} 38 / \mathrm{NF}-\mathrm{\kappa} B$ mediated inflammatory pathways. Neurobiol. Learn. Mem. 2011, 96, 156-165. [CrossRef]

45. Kaewthawee, N.; Brimson, S. The effects of ursolic acid on cytokine production via the MAPK pathways in leukemic T-cells. EXCLI J. 2013, 12, 102-114. [CrossRef] [PubMed]

46. Lu, J.; Wu, D.-M.; Zheng, Y.-L.; Hu, B.; Cheng, W.; Zhang, Z.-F.; Shan, Q. Ursolic acid improves high fat diet-induced cognitive impairments by blocking endoplasmic reticulum stress and I $\kappa$ B kinase $\beta /$ nuclear factor- $\kappa$ B-mediated inflammatory pathways in mice. Brain. Behav. Immun. 2011, 25, 1658-1667. [CrossRef]

47. Zhang, W.; Hong, D.; Zhou, Y.; Zhang, Y.; Shen, Q.; Li, J.Y.; Hu, L.H.; Li, J. Ursolic acid and its derivative inhibit protein tyrosine phosphatase 1B, enhancing insulin receptor phosphorylation and stimulating glucose uptake. Biochim. Biophys. Acta Gen. Subj. 2006, 1760, 1505-1512. [CrossRef]

48. Jayaprakasam, B.; Olson, L.K.; Schutzki, R.E.; Tai, M.H.; Nair, M.G. Amelioration of obesity and glucose intolerance in high-fat-fed C57BL/ 6 mice by anthocyanins and ursolic acid in cornelian cherry (Cornus mas). J. Agric. Food Chem. 2006, 54, 243-248. [CrossRef]

49. Best, M.M.; Duncan, C.H.; van Loon, E.J.; Wathen, J.D. Lowering of serum cholesterol by the administration of a plant sterol. Circulation 1954, 10, 201-206. [CrossRef] [PubMed]

50. Kassis, A.N.; Vanstone, C.A.; AbuMweis, S.S.; Jones, P.J.H. Efficacy of plant sterols is not influenced by dietary cholesterol intake in hypercholesterolemic individuals. Metabolism 2008, 57, 339-346. [CrossRef] [PubMed]

51. Chen, Z.Y.; Ma, K.Y.; Liang, Y.; Peng, C.; Zuo, Y. Role and classification of cholesterol-lowering functional foods. J. Funct. Foods 2011, 3, 61-69. [CrossRef]

52. Jesch, E.D.; Seo, J.M.; Carr, T.P.; Lee, J.Y. Sitosterol reduces messenger RNA and protein expression levels of Niemann-Pick C1-like 1 in FHs 74 Int cells. Nutr. Res. 2009, 29, 859-866. [CrossRef]

53. Jones, P.J.H.; MacDougall, D.E.; Ntanios, F.; Vanstone, C.A. Dietary phytosterols as cholesterol-lowering agents in humans. Can. J. Physiol. Pharmacol. 1997, 75, 217-227. [CrossRef]

54. Liang, Z.; Liang, H.; Guo, Y.; Yang, D. Cyanidin 3-o-galactoside: A natural compound with multiple health benefits. Int. J. Mol. Sci. 2021, 22, 2261. [CrossRef]

55. Kiselova-Kaneva, Y.; Galunska, B.; Nikolova, M.; Dincheva, I.; Badjakov, I. High resolution LC-MS/MS characterization of polyphenolic composition and evaluation of antioxidant activity of Sambucus ebulus fruit tea traditionally used in Bulgaria as a functional food. Food Chem. 2021, 367, 130759. [CrossRef]

56. Gu, L.; Kelm, M.A.; Hammerstone, J.F.; Beecher, G.; Holden, J.; Haytowitz, D.; Gebhardt, S.; Prior, R.L. Concentrations of Proanthocyanidins in Common Foods and Estimations of Normal Consumption. J. Nutr. 2004, 134, 613-617. [CrossRef]

57. Rivière, C.; Pawlus, A.D.; Mérillon, J.M. Natural stilbenoids: Distribution in the plant kingdom and chemotaxonomic interest in Vitaceae. Nat. Prod. Rep. 2012, 29, 1317-1333. [CrossRef] [PubMed]

58. Timmers, S.; Konings, E.; Bilet, L.; Houtkooper, R.H.; Van De Weijer, T.; Goossens, G.H.; Hoeks, J.; Van Der Krieken, S.; Ryu, D.; Kersten, S.; et al. Calorie restriction-like effects of 30 days of resveratrol supplementation on energy metabolism and metabolic profile in obese humans. Cell Metab. 2011, 14, 612-622. [CrossRef] [PubMed]

59. Espinoza, J.L.; Trung, L.Q.; Inaoka, P.T.; Yamada, K.; An, D.T.; Mizuno, S.; Nakao, S.; Takami, A. The Repeated Administration of Resveratrol Has Measurable Effects on Circulating T-Cell Subsets in Humans. Oxid. Med. Cell. Longev. 2017, $2017,6781872$. [CrossRef]

60. Yiu, E.M.; Tai, G.; Peverill, R.E.; Lee, K.J.; Croft, K.D.; Mori, T.A.; Scheiber-Mojdehkar, B.; Sturm, B.; Praschberger, M.; Vogel, A.P.; et al. An open-label trial in Friedreich ataxia suggests clinical benefit with high-dose resveratrol, without effect on frataxin levels J. Neurol. 2015, 262, 1344-1353. [CrossRef] [PubMed]

61. Crandall, J.P.; Oram, V.; Trandafirescu, G.; Reid, M.; Kishore, P.; Hawkins, M.; Cohen, H.W.; Barzilai, N. Pilot study of resveratrol in older adults with impaired glucose tolerance. Journals Gerontol. Ser. A Biol. Sci. Med. Sci. 2012, 67, 1307-1312. [CrossRef]

62. Most, J.; Timmers, S.; Warnke, I.; Jocken, J.W.; Van Boekschoten, M.; De Groot, P.; Bendik, I.; Schrauwen, P.; Goossens, G.H.; Blaak, E.E. Combined epigallocatechin-3-gallate and resveratrol supplementation for $12 \mathrm{wk}$ increases mitochondrial capacity and fat oxidation, but not insulin sensitivity, in obese humans: A randomized controlled trial. Am. J. Clin. Nutr. 2016, 104, $215-227$. [CrossRef]

63. Herrmann, K. Occurrence and content of hydroxycinnamic and hydroxybenzoic acid compounds in foods. Crit. Rev. Food Sci. Nutr. 1989, 28, 315-347. [CrossRef]

64. Weng, C.J.; Yen, G.C. Chemopreventive effects of dietary phytochemicals against cancer invasion and metastasis: Phenolic acids, monophenol, polyphenol, and their derivatives. Cancer Treat. Rev. 2012, 38, 76-87. [CrossRef] [PubMed]

65. Kim, E.O.; Min, K.J.; Kwon, T.K.; Um, B.H.; Moreau, R.A.; Choi, S.W. Anti-inflammatory activity of hydroxycinnamic acid derivatives isolated from corn bran in lipopolysaccharide-stimulated Raw 264.7 macrophages. Food Chem. Toxicol. 2012, 50, 1309-1316. [CrossRef] 
66. Hamauzu, Y.; Yasui, H.; Inno, T.; Kume, C.; Omanyuda, M. Phenolic profile, antioxidant property, and anti-influenza viral activity of Chinese quince (Pseudocydonia sinensis Schneid.), quince (Cydonia oblonga Mill.), and apple (Malus domestica Mill.) fruits. J. Agric. Food Chem. 2005, 53, 928-934. [CrossRef] [PubMed]

67. Iwai, K.; Kishimoto, N.; Kakino, Y.; Mochida, K.; Fujita, T. In vitro antioxidative effects and tyrosinase inhibitory activities of seven hydroxycinnamoyl derivatives in green coffee beans. J. Agric. Food Chem. 2004, 52, 4893-4898. [CrossRef]

68. Liu, S.L.; Peng, B.J.; Zhong, Y.L.; Liu, Y.L.; Song, Z.; Wang, Z. Effect of 5-caffeoylquinic acid on the NF-kB signaling pathway, peroxisome proliferator-activated receptor gamma 2, and macrophage infiltration in high-fat diet-fed Sprague-Dawley rat adipose tissue. Food Funct. 2015, 6, 2779-2786. [CrossRef] [PubMed]

69. Zou, Y.; Lu, Y.; Wei, D. Antioxidant activity of a flavonoid-rich extract of Hypericum perforatum L. in vitro. J. Agric. Food Chem. 2004, 52, 5032-5039. [CrossRef]

70. Mansour, S.; Djebli, N.; Ozkan, E.E.; Mat, A. In vivo antiinflammatory activity and chemical composition of Hypericum scabroides. Asian Pac. J. Trop. Med. 2014, 7, S514-S520. [CrossRef]

71. Ahn, H.; Lee, G.S. Isorhamnetin and hyperoside derived from water dropwort inhibits inflammasome activation. Phytomedicine 2017, 24, 77-86. [CrossRef]

72. Li, L.; Zhang, X.H.; Liu, G.R.; Liu, C.; Dong, Y.M. Isoquercitrin suppresses the expression of histamine and pro-inflammatory cytokines by inhibiting the activation of MAP Kinases and NF-kB in human KU812 cells. Chin. J. Nat. Med. 2016, 14, 407-412. [CrossRef]

73. Chua, L.S. A review on plant-based rutin extraction methods and its pharmacological activities. J. Ethnopharmacol. 2013, 150, 805-817. [CrossRef]

74. Wang, W.; Sun, C.; Mao, L.; Ma, P.; Liu, F.; Yang, J.; Gao, Y. The biological activities, chemical stability, metabolism and delivery systems of quercetin: A review. Trends Food Sci. Technol. 2016, 56, 21-38. [CrossRef]

75. Suganthy, N.; Devi, K.P.; Nabavi, S.F.; Braidy, N.; Nabavi, S.M. Bioactive effects of quercetin in the central nervous system: Focusing on the mechanisms of actions. Biomed. Pharmacother. 2016, 84, 892-908. [CrossRef] [PubMed]

76. Pellegatta, F.; Bertelli, A.A.E.; Staels, B.; Duhem, C.; Fulgenzi, A.; Ferrero, M.E. Different short- and long-term effects of resveratrol on nuclear factor- $\mathrm{kB}$ phosphorylation and nuclear appearance in human endothelial cells. Am. J. Clin. Nutr. 2003, 77, 1220-1228. [CrossRef]

77. Norata, G.D.; Marchesi, P.; Passamonti, S.; Pirillo, A.; Violi, F.; Catapano, A.L. Anti-inflammatory and anti-atherogenic effects of cathechin, caffeic acid and trans-resveratrol in apolipoprotein E deficient mice. Atherosclerosis 2007, 191, 265-271. [CrossRef]

78. Hou, D.X.; Yanagita, T.; Uto, T.; Masuzaki, S.; Fujii, M. Anthocyanidins inhibit cyclooxygenase-2 expression in LPS-evoked macrophages: Structure-activity relationship and molecular mechanisms involved. Biochem. Pharmacol. 2005, 70, 417-425. [CrossRef] [PubMed]

79. Pergola, C.; Rossi, A.; Dugo, P.; Cuzzocrea, S.; Sautebin, L. Inhibition of nitric oxide biosynthesis by anthocyanin fraction of blackberry extract. Nitric Oxide-Biol. Chem. 2006, 15, 30-39. [CrossRef] [PubMed]

80. Karlsen, A.; Retterstøl, L.; Laake, P.; Paur, I.; Bøhn, S.K.; Sandvik, L.; Blomhoff, R. Anthocyanins inhibit nuclear factor-kappaB activation in monocytes and reduce plasma concentrations of pro-inflammatory mediators in healthy adults. J. Nutr. 2007, 137, 1951-1954. [CrossRef]

81. Kim, J.; Kim, H.; Choi, H.; Jo, A.; Kang, H.; Yun, H.; Im, S.; Choi, C. Anti-inflammatory effects of a stauntonia hexaphylla fruit extract in lipopolysaccharide-activated RAW-264.7 macrophages and rats by carrageenan-induced hind paw swelling. Nutrients 2018, 10, 110. [CrossRef] [PubMed]

82. Schwaiger, S.; Zeller, I.; Pölzelbauer, P.; Frotschnig, S.; Laufer, G.; Messner, B.; Pieri, V.; Stuppner, H.; Bernhard, D. Identification and pharmacological characterization of the anti-inflammatory principal of the leaves of dwarf elder (Sambucus ebulus L.). J. Ethnopharmacol. 2011, 133, 704-709. [CrossRef]

83. van de Stolpe, A.; Caldenhoven, E.; Stade, B.G.; Koenderman, L.; Raaijmakers, J.A.; Johnson, J.P.; van der Saag, P.T. 12-Otetradecanoylphorbol-13-acetate- and tumor necrosis factor alpha-mediated induction of intercellular adhesion molecule-1 is inhibited by dexamethasone. Functional analysis of the human intercellular adhesion molecular-1 promoter. J. Biol. Chem. 1994, 269, 6185-6192. [CrossRef]

84. Ueda, A.; Okuda, K.; Ohno, S.; Shirai, A.; Igarashi, T.; Matsunaga, K.; Fukushima, J.; Kawamoto, S.; Ishigatsubo, Y.; Okubo, T. NF-kappa B and Sp1 regulate transcription of the human monocyte chemoattractant protein-1 gene. J. Immunol. 1994, 153, 2052-2063. [CrossRef]

85. Hsieh, I.-N.; Chang, A.S.-Y.; Teng, C.-M.; Chen, C.-C.; Yang, C.-R. Aciculatin inhibits lipopolysaccharide-mediated inducible nitric oxide synthase and cyclooxygenase-2 expression via suppressing NF- $\mathrm{kB}$ and JNK/p38 MAPK activation pathways. J. Biomed. Sci. 2011, 18, 28. [CrossRef]

86. Tan, K.S.; Qian, L.; Rosado, R.; Flood, P.M.; Cooper, L.F. The role of titanium surface topography on J774A.1 macrophage inflammatory cytokines and nitric oxide production. Biomaterials 2006, 27, 5170-5177. [CrossRef] [PubMed]

87. Kim, M.S.; Park, S.B.; Suk, K.; Kim, I.K.; Kim, S.Y.; Kim, J.A.; Lee, S.H.; Kim, S.H. Gallotannin isolated from Euphorbia species, 1,2,6-tri-O-galloyl- $\beta$-D- allose, decreases nitric oxide production through inhibition of nuclear factor- $\kappa \mathrm{B}$ and downstream inducible nitric oxide synthase expression in macrophages. Biol. Pharm. Bull. 2009, 32, 1053-1056. [CrossRef] [PubMed] 
88. Maraslioglu, M.; Oppermann, E.; Blattner, C.; Weber, R.; Henrich, D.; Jobin, C.; Schleucher, E.; Marzi, I.; Lehnert, M. Chronic ethanol feeding modulates inflammatory mediators, activation of nuclear factor- $\mathrm{B}$, and responsiveness to endotoxin in murine kupffer cells and circulating leukocytes. Mediat. Inflamm. 2014, 2014, 808695. [CrossRef] [PubMed]

89. Zhu, Y.; Zhu, M.; Lance, P. INOS signaling interacts with COX-2 pathway in colonic fibroblasts. Exp. Cell Res. 2012, 318, 2116-2127. [CrossRef]

90. Barak, V.; Halperin, T.; Kalickman, I. The effect of Sambucol, a black elderberry-based, natural product, on the production of human cytokines: I. Inflammatory cytokines. Eur. Cytokine Netw. 2001, 12, 290-296.

91. Drummond, G.R.; Selemidis, S.; Griendling, K.K.; Sobey, C.G. Combating oxidative stress in vascular disease: NADPH oxidases as therapeutic targets. Nat. Rev. Drug Discov. 2011, 10, 453-471. [CrossRef]

92. Blough, N.V.; Zafiriou, O.C. Reaction of Superoxide with Nitric Oxide to Form Peroxonitrite in Alkaline Aqueous Solution. Inorg. Chem. 1985, 24, 3502-3504. [CrossRef]

93. Gryglewski, R.J.; Palmer, R.M.J.; Moncada, S. Superoxide anion is involved in the breakdown of endothelium-derived vascular relaxing factor. Nature 1986, 320, 454-456. [CrossRef]

94. Leto, T.L.; Geiszt, M. Role of Nox family NADPH oxidases in host defense. Antioxidants Redox Signal. 2006, 8, $1549-1561$. [CrossRef]

95. Guzik, T.J.; Harrison, D.G. Vascular NADPH oxidases as drug targets for novel antioxidant strategies. Drug Discov. Today 2006, 11, 524-533. [CrossRef] [PubMed]

96. Abo, A.; Pick, E.; Hall, A.; Totty, N.; Teahan, C.G.; Segal, A.W. Activation of the NADPH oxidase involves the small GTP-binding protein p21rac1. Nature 1991, 353, 668-670. [CrossRef] [PubMed]

97. Potenza, M.A.; Marasciulo, F.L.; Tarquinio, M.; Tiravanti, E.; Colantuono, G.; Federici, A.; Kim, J.A.; Quon, M.J.; Montagnani, M. EGCG, a green tea polyphenol, improves endothelial function and insulin sensitivity, reduces blood pressure, and protects against myocardial I/R injury in SHR. Am. J. Physiol.—Endocrinol. Metab. 2007, 292, E1378-E1387. [CrossRef] [PubMed]

98. Galindo, P.; González-Manzano, S.; Zarzuelo, M.J.; Gómez-Guzmán, M.; Quintela, A.M.; González-Paramás, A.; Santos-Buelga, C.; Pérez-Vizcaíno, F.; Duarte, J.; Jiménez, R. Different cardiovascular protective effects of quercetin administered orally or intraperitoneally in spontaneously hypertensive rats. Food Funct. 2012, 3, 643-650. [CrossRef]

99. Sánchez, M.; Galisteo, M.; Vera, R.; Villar, I.C.; Zarzuelo, A.; Tamargo, J.; Pérez-Vizcaíno, F.; Duarte, J. Quercetin downregulates NADPH oxidase, increases eNOS activity and prevents endothelial dysfunction in spontaneously hypertensive rats. J. Hypertens. 2006, 24, 75-84. [CrossRef]

100. Sanchez, M.; Lodi, F.; Vera, R.; Villar, I.C.; Cogolludo, A.; Jimenez, R.; Moreno, L.; Romero, M.; Tamargo, J.; Perez-Vizcaino, F.; et al. Quercetin and isorhamnetin prevent endothelial dysfunction, superoxide production, and overexpression of p47phox induced by angiotensin II in rat aorta. J. Nutr. 2007, 137, 910-915. [CrossRef]

101. Ihm, S.H.; Lee, J.O.; Kim, S.J.; Seung, K.B.; Schini-Kerth, V.B.; Chang, K.; Oak, M.H. Catechin prevents endothelial dysfunction in the prediabetic stage of OLETF rats by reducing vascular NADPH oxidase activity and expression. Atherosclerosis 2009, 206, 47-53. [CrossRef]

102. Schilder, Y.D.C.; Heiss, E.H.; Schachner, D.; Ziegler, J.; Reznicek, G.; Sorescu, D.; Dirsch, V.M. NADPH oxidases 1 and 4 mediate cellular senescence induced by resveratrol in human endothelial cells. Free Radic. Biol. Med. 2009, 46, 1598-1606. [CrossRef] [PubMed]

103. Gu, Y.; Xu, Y.C.; Wu, R.F.; Nwariaku, F.E.; Souza, R.F.; Flores, S.C.; Terada, L.S. p47phox participates in activation of RelA in endothelial cells. J. Biol. Chem. 2003, 278, 17210-17217. [CrossRef]

104. Makowski, L.; Boord, J.B.; Maeda, K.; Babaev, V.R.; Uysal, K.T.; Morgan, M.A.; Parker, R.A.; Suttles, J.; Fazio, S.; Hotamisligil, G.S.; et al. Lack of macrophage fatty-acid-binding protein $\mathrm{aP} 2$ protects mice deficient in apolipoprotein $\mathrm{E}$ against atherosclerosis. Nat. Med. 2001, 7, 699-705. [CrossRef] [PubMed]

105. Kazemi, M.R.; McDonald, C.M.; Shigenaga, J.K.; Grunfeld, C.; Feingold, K.R. Adipocyte fatty acid-binding protein expression and lipid accumulation are increased during activation of murine macrophages by toll-like receptor agonists. Arterioscler. Thromb. Vasc. Biol. 2005, 25, 1220-1224. [CrossRef] [PubMed]

106. Furuhashi, M.; Fucho, R.; Görgün, C.Z.; Tuncman, G.; Cao, H.; Hotamisligil, G.S. Adipocyte/macrophage fatty acid-binding proteins contribute to metabolic deterioration through actions in both macrophages and adipocytes in mice. J. Clin. Investig. 2008, 118, 2640-2650. [CrossRef] [PubMed]

107. Furuhashi, M.; Tuncman, G.; Görgün, C.Z.; Makowski, L.; Atsumi, G.; Vaillancourt, E.; Kono, K.; Babaev, V.R.; Fazio, S.; Linton, M.F.; et al. Treatment of diabetes and atherosclerosis by inhibiting fatty-acid-binding protein aP2. Nature 2007, 447, 959-965. [CrossRef]

108. Milne, J.C.; Lambert, P.D.; Schenk, S.; Carney, D.P.; Smith, J.J.; Gagne, D.J.; Jin, L.; Boss, O.; Perni, R.B.; Vu, C.B.; et al. Small molecule activators of SIRT1 as therapeutics for the treatment of type 2 diabetes. Nature 2007, 450, 712-716. [CrossRef]

109. Csiszar, A.; Labinskyy, N.; Podlutsky, A.; Kaminski, P.M.; Wolin, M.S.; Zhang, C.; Mukhopadhyay, P.; Pacher, P.; Hu, F.; De Cabo, R.; et al. Vasoprotective effects of resveratrol and SIRT1: Attenuation of cigarette smoke-induced oxidative stress and proinflammatory phenotypic alterations. Am. J. Physiol.-Heart Circ. Physiol. 2008, 294, 2721-2735. [CrossRef]

110. Yoshizaki, T.; Milne, J.C.; Imamura, T.; Schenk, S.; Sonoda, N.; Babendure, J.L.; Lu, J.-C.; Smith, J.J.; Jirousek, M.R.; Olefsky, J.M. SIRT1 Exerts Anti-Inflammatory Effects and Improves Insulin Sensitivity in Adipocytes. Mol. Cell. Biol. 2009, 29, $1363-1374$. [CrossRef] 
111. Yu, C.; Chen, Y.; Cline, G.W.; Zhang, D.; Zong, H.; Wang, Y.; Bergeron, R.; Kim, J.K.; Cushman, S.W.; Cooney, G.J.; et al. Mechanism by which fatty acids inhibit insulin activation of insulin receptor substrate-1 (IRS-1)-associated phosphatidylinositol 3-kinase activity in muscle. J. Biol. Chem. 2002, 277, 50230-50236. [CrossRef]

112. Bettigole, S.E.; Glimcher, L.H. Endoplasmic reticulum stress in immunity. Annu. Rev. Immunol. 2015, 33, 107-138. [CrossRef]

113. Li, S.; Ye, L.; Yu, X.; Xu, B.; Li, K.; Zhu, X.; Liu, H.; Wu, X.; Kong, L. Hepatitis C virus NS4B induces unfolded protein response and endoplasmic reticulum overload response-dependent NF-kB activation. Virology 2009, 391, 257-264. [CrossRef]

114. Randjelović, P.; Veljković, S.; Stojiljković, N.; Sokolović, D.; Ilić, I.; Laketić, D.; Randjelović, D.; Randjelović, N. The beneficial biological properties of salicylic acid. Acta Fac. Med. Naissensis 2015, 32, 259-265. [CrossRef]

115. Yoshiuchi, K.; Kaneto, H.; Matsuoka, T.A.; Kohno, K.; Iwawaki, T.; Nakatani, Y.; Yamasaki, Y.; Hori, M.; Matsuhisa, M. Direct monitoring of in vivo ER stress during the development of insulin resistance with ER stress-activated indicator transgenic mice. Biochem. Biophys. Res. Commun. 2008, 366, 545-550. [CrossRef]

116. Boden, G.; Duan, X.; Homko, C.; Molina, E.J.; Song, W.; Perez, O.; Cheung, P.; Merali, S. Increase in endoplasmic reticulum stress-related proteins and genes in adipose tissue of obese, insulin-resistant individuals. Diabetes 2008, 57, 2438-2444. [CrossRef]

117. Sharma, N.K.; Das, S.K.; Mondal, A.K.; Hackney, O.G.; Chu, W.S.; Kern, P.A.; Rasouli, N.; Spencer, H.J.; Yao-Borengasser, A.; Elbein, S.C. Endoplasmic reticulum stress markers are associated with obesity in nondiabetic subjects. J. Clin. Endocrinol. Metab. 2008, 93, 4532-4541. [CrossRef] [PubMed]

118. Eizirik, D.L.; Cardozo, A.K.; Cnop, M. The role for endoplasmic reticulum stress in diabetes mellitus. Endocr. Rev. 2008, 29 , 42-61. [CrossRef]

119. Lin, J.H.; Walter, P.; Yen, T.S.B. Endoplasmic reticulum stress in disease pathogenesis. Annu. Rev. Pathol. Mech. Dis. 2008, 3, 399-425. [CrossRef] [PubMed]

120. Ron, D.; Hubbard, S.R. How IRE1 Reacts to ER Stress. Cell 2008, 132, 24-26. [CrossRef] [PubMed]

121. Ron, D.; Walter, P. Signal integration in the endoplasmic reticulum unfolded protein response. Nat. Rev. Mol. Cell Biol. 2007, 8, 519-529. [CrossRef]

122. Tsukano, H.; Gotoh, T.; Endo, M.; Miyata, K.; Tazume, H.; Kadomatsu, T.; Yano, M.; Iwawaki, T.; Kohno, K.; Araki, K.; et al. The endoplasmic reticulum stress-C/EBP homologous protein pathway-mediated apoptosis in macrophages contributes to the instability of atherosclerotic plaques. Arterioscler. Thromb. Vasc. Biol. 2010, 30, 1925-1932. [CrossRef] [PubMed]

123. Li, G.; Scull, C.; Ozcan, L.; Tabas, I. NADPH oxidase links endoplasmic reticulum stress, oxidative stress, and PKR activation to induce apoptosis. J. Cell Biol. 2010, 191, 1113-1125. [CrossRef]

124. Pahl, H.L.; Baeuerle, P.A. Activation of NF- $\mathrm{BB}$ by ER stress requires both ca2+ and reactive oxygen intermediates as messengers. FEBS Lett. 1996, 392, 129-136. [CrossRef]

125. Deng, J.; Lu, P.D.; Zhang, Y.; Scheuner, D.; Kaufman, R.J.; Sonenberg, N.; Harding, H.P.; Ron, D. Translational Repression Mediates Activation of Nuclear Factor Kappa B by Phosphorylated Translation Initiation Factor 2. Mol. Cell. Biol. 2004, 24, 10161-10168. [CrossRef]

126. Livak, K.J.; Schmittgen, T.D. Analysis of relative gene expression data using real-time quantitative PCR and the 2- $\Delta \Delta C T$ method. Methods 2001, 25, 402-408. [CrossRef] [PubMed]

127. Martínez-Sánchez, N.; Seoane-Collazo, P.; Contreras, C.; Varela, L.; Villarroya, J.; Rial-Pensado, E.; Buqué, X.; Aurrekoetxea, I.; Delgado, T.C.; Vázquez-Martínez, R.; et al. Hypothalamic AMPK-ER Stress-JNK1 Axis Mediates the Central Actions of Thyroid Hormones on Energy Balance. Cell Metab. 2017, 26, 212-229.e12. [CrossRef] [PubMed]

128. González-García, I.; Contreras, C.; Estévez-Salguero, Á.; Ruíz-Pino, F.; Colsh, B.; Pensado, I.; Liñares-Pose, L.; Rial-Pensado, E.; Martínez de Morentin, P.B.; Fernø, J.; et al. Estradiol Regulates Energy Balance by Ameliorating Hypothalamic Ceramide-Induced ER Stress. Cell Rep. 2018, 25, 413-423.e5. [CrossRef] [PubMed] 